\title{
The Term Structure of Variance Swap Rates and Optimal Variance Swap Investments
}

\author{
Daniel Egloff, Markus Leippold, and Liuren Wu*
}

\begin{abstract}
This paper performs specification analysis on the term structure of variance swap rates on the S\&P 500 index and studies the optimal investment decision on the variance swaps and the stock index. The analysis identifies 2 stochastic variance risk factors, which govern the short and long end of the variance swap term structure variation, respectively. The highly negative estimate for the market price of variance risk makes it optimal for an investor to take short positions in a short-term variance swap contract, long positions in a long-term variance swap contract, and short positions in the stock index.
\end{abstract}

\section{Introduction}

The financial market is becoming increasingly aware of the fact that the return variance on stock indexes is stochastic (Engle (2004)) and the variance risk is heavily priced (Carr and $\mathrm{Wu}(2009)$ ). Associated with this recognition is the development of a large number of variance-related derivative products. The most actively traded is the variance swap contract. The contract has 0 value at inception. At maturity, the long side of the variance swap contract receives the difference between a standard measure of the realized variance and a fixed rate, called the variance swap rate, determined at the inception of the contract. Traditional derivative contracts such as calls, puts, and straddles also have variance risk exposure,

\footnotetext{
*Egloff, daniel.egloff@quantcatalyst.com, QuantCatalyst, Hardturmstrasse 101, 8005 Zurich, Switzerland; Leippold, leippold@isb.uzh.ch, University of Zurich, Swiss Banking Institute, Plattenstrasse 14, 8032 Zurich, Switzerland; and Wu, liuren.wu@baruch.cuny.edu, Baruch College, Zicklin School of Business, One Bernard Baruch Way, Box B10-225, New York, NY 10010. We thank Dave Backus, Cliff Ball, Craig Brown, Stephen Brown (the editor), Peter Carr, Jaksa Cvitanic, Stephen Figlewski, Gikas A. Hardouvelis, Robert Kosowski, Craig Lewis, Dilip Madan (the referee), Dimitrios Malliaropoulos, Loriano Mancini, Nour Meddahi, Carsten Murawski, Bob Schwartz, Clemens Sialm, George Skiadopoulos, Hans Stoll, Anders Trolle, Jun Wang, Bob Whaley, Rudi Zagst, and the seminar participants at Baruch College, Imperial College, Technische Universität München, University of Munich, University of Piraeus, Vanderbilt University, the 2006 European Finance Association (EFA) Meetings in Zurich, and the 2007 Institute for Quantitative Investment Research (INQUIRE) Europe meeting in Oslo for comments. The authors gratefully acknowledge the financial support of INQUIRE Europe, the Swiss National Science Foundation (National Centre of Competence in Research in "Financial Valuation and Risk Management" (NCCR FINRISK)), and Baruch College.
} 
but entering a variance swap contract represents the most direct way of achieving exposure to or hedging against variance risk.

Variance swap contracts on major equity indexes are actively traded over the counter. Variance swap rate quotes on such indexes are now readily available from several broker dealers. In this paper, we obtain more than a decade's worth of variance swap rate quotes from a major investment bank on the Standard \& Poor's (S\&P) 500 index at 5 fixed times to maturity, from 2 months to 2 years. With the data, we perform specification analysis on the variance risk dynamics and the term structure of variance swap rates. We propose a class of models on the variance risk dynamics and derive their pricing implications on the term structure of variance swap rates. We estimate the model specifications by exploiting the rich information embedded in both the time series and the term structure of the variance swap rate quotes. Based on the estimated variance risk dynamics, we study both theoretically and empirically how investors can use the term structure of variance swap contracts to span the variance risk and to revise their dynamic asset allocation decisions.

Our specification analysis and model estimation show that 2 stochastic variance risk factors are needed to explain the term structure variation of the variance swap rates, with 1 factor controlling the instantaneous variance rate variation and the other controlling the central tendency variation of the return variance. The instantaneous variance rate is much more transient than the central tendency factor under both the risk-neutral and the statistical measures. Thus, the 2 factors generate different loading patterns across the term structure of the variance swap rates. The instantaneous variance rate factor dominates the short-term variance swap rate dynamics, whereas the central tendency factor dominates the long-term variance swap rate dynamics.

With the estimated variance risk dynamics, we study how the presence of variance swap contracts across several maturities alters an investor's optimal asset allocation decision. We consider a dynamic asset allocation problem, where an investor equipped with a constant relative risk aversion (CRRA) utility function allocates her initial wealth among the money market account, the S\&P 500 stock index, and variance swap contracts at different maturities on the index to maximize her utility of terminal wealth. We derive the optimal allocation decisions in analytical forms for cases with and without the availability of the variance swap contracts in the investment.

In the absence of the variance swap contracts, the presence of stochastic variance and its correlation with the index return creates an intertemporal hedging demand for the stock index investment. However, with the variance swap contracts directly spanning the variance risk, there no longer exists an intertemporal hedging demand for the stock index investment. Under 2-factor variance risk dynamics, we can use 2 variance swap contracts at 2 distinct maturities to span the variance risk. The optimal investments in the stock index and the 2 variance swap contracts depend on the market prices of the 3 sources of risks: the return risk, the instantaneous variance rate risk, and the variance central tendency risk. The highly negative estimate for the market price of the instantaneous variance risk makes it optimal to take short positions in a short-term variance swap contract, long positions in a long-term variance swap contract, and short positions in 
the stock index. When we perform a historical analysis on different investment strategies, we find that incorporating variance swap contracts into the portfolio mix significantly increases the historical performance of the investment.

The remainder of the paper is organized as follows. Section II discusses the literature that forms the background of our study. Section III introduces a class of affine stochastic variance models, under which we value the term structure of variance swap rates. Section IV discusses the data, estimation strategy, and estimation results on variance risk dynamics and variance risk premium, and their effects on the variance swap term structure. Section $V$ derives the optimal asset allocation decisions with and without the variance swap contracts. Section VI calibrates the allocation decisions to the estimated risk dynamics and risk premiums and studies the historical performance of different investment strategies. Section VII concludes.

\section{Background}

Our study is related to several strands of literature. The first strand includes all traditional studies that estimate the variance dynamics joint with the return dynamics (see Engle (2004) for a review). More recently, a rapidly growing literature infers the variance dynamics based on realized variance estimators constructed from high-frequency returns. Important contributions include Andersen, Bollerslev, Diebold, and Ebens (2001), Andreou and Ghysels (2002), Andersen, Bollerslev, Diebold, and Labys (2003), Barndorff-Nielsen and Shephard (2004a), (2004b), Aït-Sahalia, Mykland, and Zhang (2005), Andersen, Bollerslev, and Meddahi (2005), Oomen (2005), Zhang, Mykland, and Aït-Sahalia (2005), Bandi and Russell (2006), Hansen and Lunde (2006), and Aït-Sahalia and Mancini (2008). The realized variance estimators make return variance almost an observable quantity and hence sharpen the identification of variance dynamics. In this paper, we also use realized variance in combination with our variance swap quotes to enhance the identification of the variance risk dynamics and variance risk premium. Nevertheless, we do not construct the realized variance estimators using high-frequency returns, but using daily returns in accordance with the specification of a typical variance swap contract.

The second strand of literature combines information in time-series returns and option prices to infer the variance dynamics and variance risk premium together with the return dynamics and return risk premium. Prominent examples include Bates (1996), (2000), (2003), Chernov and Ghysels (2000), Jackwerth (2000), Pan (2002), Jones (2003), Eraker (2004), Ait-Sahalia and Kimmel (2007), Broadie, Chernov, and Johannes (2007), and Carr and Wu (2008). Bergomi (2004) highlights how traditional stochastic volatility and Lévy jump models impose structural constraints on the relations between the Black and Scholes (1973) implied volatility skew along the strike dimension, the spot-volatility correlation, and the term structure of the volatility of volatility. With variance swap rate quotes, we show that we can directly estimate the variance dynamics and variance risk premium without specifying the underlying return dynamics.

Several studies form option portfolios to separate the variance risk exposure from the return risk exposure. For example, Bakshi and Kapadia (2003a), 
(2003b) consider the profit and loss arising from delta-hedging a long position in a call option. Carr and Wu (2009) use a portfolio of vanilla options to approximate the value of the 30-day variance swap rate on 5 stock indexes and 35 individual stocks. They compare the synthetic 30-day variance swap rates to the ex post realized variance to determine the variance risk premium. Bondarenko (2004) uses a similar procedure to synthesize variance swap rates on the S\&P 500 index and link the variance risk premium to hedge fund behavior. Wu (2010) estimates the variance risk dynamics and variance risk premium by combining the information in realized variance estimators from high-frequency returns and the VIX, a volatility index on the S\&P 500 index constructed by the Chicago Board of Options Exchange to approximate the 30-day variance swap rate (Carr and $\mathrm{Wu}$ (2006)). Unlike these studies, we obtain direct variance swap rate quotes and thus avoid the approximation errors inherent in the procedure of synthesizing variance swaps from vanilla options (Carr, Lee, and Wu (2010)). Furthermore, by having variance swap rates across several maturities, we can more effectively identify the multidimensional structure of the variance risk dynamics and their impacts on the variance swap term structure and variance swap investment.

Our investment analysis is related to a strand of literature that studies asset allocation problems in the presence of derivative securities. Carr and Madan (2001) and Carr, Jin, and Madan (2001) study how to use vanilla options across different strikes to span the jump risk with random jump size, in the absence of stochastic variance. Complementary to their study, we focus on how to use variance swap contracts of different maturities to span the multidimensional stochastic variance risk. Liu and Pan (2003) analyze investments in vanilla options in the presence of both jumps and stochastic variance. In this case, the allocation to a vanilla option at a given strike and maturity is a result of mixed effects from spanning the jump risk and the stochastic variance risk. To disentangle the effects, they assume a constant jump size and hence effectively seclude themselves from the strike dimension analyzed in Carr, Jin, and Madan. Compared to the options contracts, variance swap contracts provide a more direct way of spanning the variance risk. Since the variance swap is a linear contract in variance risk, by trading these contracts, the investor does not create additional delta exposures to the underlying stock index, as would be the case for strategies involving vanilla options.

Finally, recognizing the virtue of the variance swap contract as a traded asset with the most direct (and linear) exposure to variance risk, several researchers propose to directly model the dynamics of the variance swap rate (Duanmu (2004), Carr and Sun (2007)) or the forward variance swap rate (Dupire (1993), Bergomi (2005), (2008), and Buehler (2006)). In particular, Bergomi takes the initial forward variance swap rate curve as given and models the dynamics of the logarithm of forward variance rate as controlled by multiple factors. By contrast, we start with the instantaneous variance rate as an affine function of a finite number of factors and derive the fair value for the variance swap term structure. While Bergomi's direct modeling of the forward variance swap rate curve can prove useful for pricing volatility derivatives and exotic structures, our finitedimensional factor model provides fair valuation on the variance swap term structure. 


\section{Affine Models of Variance Swap Term Structure}

We start with a complete stochastic basis $\left(\Omega, \mathcal{F},\left(\mathcal{F}_{t}\right)_{t \geq 0}, \mathbb{P}\right)$, with $\mathbb{P}$ being the statistical probability measure. We use $\mathbb{Q}$ to denote a risk-neutral measure that is absolutely continuous with respect to $\mathbb{P}$. No arbitrage guarantees that there exists at least one such measure that prices all traded securities (Duffie (1992)).

We use $v_{t}$ to denote the time- $t$ instantaneous variance rate, and use $V_{t, T} \equiv$ $\int_{t}^{T} v_{s} d s$ to denote the aggregate return variance during the period $[t, T]$, with $\tau=T-t$ being the length of the horizon. We assume that the dynamics of the instantaneous variance rate $v_{t}$ is controlled by a $k$-dimensional Markov process $X$, satisfying the following stochastic differential equation under measure $\mathbb{Q}$ :

$$
d X_{t}=\mu\left(X_{t}\right) d t+\Sigma^{X}(X) d B_{t}^{X}+\left(q d N^{X}\left(\lambda\left(X_{t}\right)\right)-\bar{q} \lambda\left(X_{t}\right) d t\right),
$$

where $\mu\left(X_{t}\right) \in \mathbb{R}^{k}$ denotes the instantaneous drift function, $B^{X}$ denotes a $k$ dimensional independent Brownian motion with $\Sigma^{X}(X) \Sigma^{X}(X)^{\top} \in \mathbb{R}^{k \times k}$ being the symmetric and positive definite instantaneous covariance matrix, and $N^{X}$ denotes $k$ independent Cox (1955) processes with intensities $\lambda\left(X_{t}\right) \in \mathbb{R}^{k}$ and with the random jump magnitudes $q$ being a diagonal $(k \times k)$ matrix, characterized by its 2-sided Laplace transform $\mathcal{L}_{q}(\cdot)$ and with $\bar{q}=\mathbb{E}^{\mathbb{Q}}[q]$.

To analyze the variance risk dynamics using variance swap rates, we adopt the affine framework of Duffie, Pan, and Singleton (2000).

Definition 1. In affine stochastic variance models, the Laplace transform of the aggregate variance $V_{t, T}$ under the risk-neutral measure $\mathbb{Q}$ is an exponential-affine function of the state vector $X_{t}$ :

$$
\mathcal{L}_{V}(u) \equiv \mathbb{E}^{\mathbb{Q}}\left[e^{-u V_{t, T}} \mid \mathcal{F}_{t}\right]=\exp \left(-\mathbf{b}(\tau)^{\top} X_{t}-c(\tau)\right),
$$

where $\mathbf{b}(\tau) \in \mathbb{R}^{k}$ and $c(\tau)$ is a scalar.

We confine our attention to time-homogeneous models by constraining the coefficients $(\mathbf{b}(\tau), c(\tau))$ to depend only on the horizon $\tau=T-t$ but not on the calendar time $t$. Proposition 1 presents a set of sufficient conditions for the affine definition in equation (2) to hold.

Proposition 1. If the instantaneous variance rate $v_{t}$, the drift vector $\mu(X)$, the diffusion covariance matrix $\Sigma^{X}(X) \Sigma^{X}(X)^{\top}$, and the jump arrival rate $\lambda(X)$ of the Markov process $X$ are all affine in $X$ under the risk-neutral measure $\mathbb{Q}$, the Laplace transform $\mathcal{L}_{V}(u)$ is exponential affine in $X_{t}$.

We parameterize the affine conditions as

$$
\begin{aligned}
v_{t} & =\mathbf{b}_{v}^{\top} X_{t}+c_{v}, \quad \mathbf{b}_{v} \in \mathbb{R}^{k}, c_{v} \in \mathbb{R}, \\
\mu\left(X_{t}\right) & =\kappa\left(\theta-X_{t}\right), \quad \kappa \in \mathbb{R}^{k \times k}, \theta \in \mathbb{R}^{k}, \\
\Sigma^{X}(X) \Sigma^{X}(X)^{\top} & =\operatorname{diag}\left[\alpha+\beta X_{t}\right], \quad \alpha \in \mathbb{R}^{k}, \beta \in \mathbb{R}^{k \times k}, \\
\lambda\left(X_{t}\right) & =\alpha_{\lambda}+\beta_{\lambda} X_{t}, \quad \alpha_{\lambda} \in \mathbb{R}^{k}, \beta_{\lambda} \in \mathbb{R}^{k \times k},
\end{aligned}
$$

where we adopt the convention that $\operatorname{diag}[v]$ maps the vector $v$ onto a diagonal matrix and diag $[M]$ maps the diagonal elements of the matrix $M$ onto a vector. We further constrain $\beta$ and $\beta_{\lambda}$ to be diagonal matrices. Then, the coefficients 
$(\mathbf{b}(\tau), c(\tau))$ for the Laplace transform in equation (2) are determined by the following ordinary differential equations:

$$
\begin{aligned}
\mathbf{b}^{\prime}(\tau)= & u \mathbf{b}_{v}-\left(\kappa+\bar{q} \beta_{\lambda}\right)^{\top} \mathbf{b}(\tau)-\frac{1}{2} \beta \operatorname{diag}\left[\mathbf{b}(\tau) \mathbf{b}(\tau)^{\top}\right] \\
& -\beta_{\lambda}\left(\mathcal{L}_{q}(\mathbf{b}(\tau))-1\right), \\
c^{\prime}(\tau)= & u c_{v}+\left(\kappa \theta-\bar{q} \alpha_{\lambda}\right)^{\top} \mathbf{b}(\tau)-\frac{1}{2} \alpha^{\top} \operatorname{diag}\left[\mathbf{b}(\tau) \mathbf{b}(\tau)^{\top}\right] \\
& -\alpha_{\lambda}^{\top}\left(\mathcal{L}_{q}(\mathbf{b}(\tau))-1\right),
\end{aligned}
$$

with the boundary conditions $\mathbf{b}(0)=0$ and $c(0)=0$.

\section{A. The Term Structure of Variance Swap Rates}

The terminal payoff of a variance swap contract is the difference between the realized variance over a certain time period and a fixed variance swap rate, determined at the inception of the contract. The variance difference is multiplied by a notional amount that converts the difference into dollars. Since the contract is worth 0 at inception, no arbitrage dictates that the time- $t$ variance swap rate with expiry date $T, \mathrm{VS}_{t}(T)$, is equal to the risk-neutral expected value of the aggregate return variance over the horizon $[t, T]$,

$$
\operatorname{VS}_{t}(T)=\frac{1}{\tau} \mathbb{E}_{t}^{\mathbb{Q}}\left[V_{t, T}\right], \quad \tau=T-t
$$

where the $1 / \tau$ scaling represents an annualization in the variance swap rate quote.

Under the affine class in equation (2), the expectation can be obtained from the Laplace transform,

$\mathbb{E}_{t}^{\mathbb{Q}}\left[V_{t, T}\right]=\left.\mathcal{L}_{V}(u)\left(\left[\frac{\partial \mathbf{b}(\tau)}{\partial u}\right]^{\top} X_{t}+\frac{\partial c(\tau)}{\partial u}\right)\right|_{u=0}=\mathbf{B}(\tau)^{\top} X_{t}+C(\tau)$,

which is affine in the current level of the state vector $X_{t}$. Note that $\left.\mathcal{L}_{V_{t, T}}(u)\right|_{u=0}=1$ and the coefficients $\mathbf{B}(\tau)$ and $C(\tau)$ are defined as the partial derivatives of $\mathbf{b}(\tau)$ and $c(\tau)$ with respect to $u$.

Proposition 2. Under the affine stochastic variance framework as specified in (3), the time- $t$ variance swap rates are affine in the state vector $X_{t}$,

$$
\operatorname{VS}_{t}(T)=\frac{1}{\tau}\left[\mathbf{B}(\tau)^{\top} X_{t}+C(\tau)\right]
$$

with

$$
\begin{aligned}
\mathbf{B}(\tau) & =\left(I-e^{-\kappa^{\top} \tau}\right)\left(\kappa^{\top}\right)^{-1} \mathbf{b}_{v}, \\
C(\tau) & =\left(c_{v}+\mathbf{b}_{v}^{\top} \theta\right) \tau-\mathbf{B}(\tau)^{\top} \theta .
\end{aligned}
$$

Due to space constraints, we omit the proofs for this and subsequent propositions. They are available from the authors. From Proposition 2, we obtain the following corollary: 
Corollary 1. Under the affine stochastic variance framework, the term structure of the return variance swap rate only depends on the specification of the drift of the state vector but does not depend upon the type and specification of the martingale component of these factors. Holding constant the long-run mean and the reverting speed, the term structure remains the same whether the martingale component is a pure diffusion, a pure jump martingale, or a mixture of both.

The corollary follows readily by inspecting the solutions of the coefficients $(\mathbf{B}(\tau), C(\tau))$ in equation (7). The parameters controlling the covariance matrix of the diffusion component $(\alpha, \beta)$ and the parameters for the jump component $\left(\alpha_{\lambda}, \beta_{\lambda}, \mathcal{L}_{q}(\cdot)\right)$ do not enter these coefficients. The corollary suggests that from the term structure of the return variance swap, one can identify the risk-neutral drift of the state vector that controls the dynamics of the return variance. Nevertheless, the innovation (martingale) specifications of the instantaneous variance rate play little role in determining the term structure of the variance swap, although they do affect the time-series behavior of the variance swap rates and the pricing of variance swap options.

We use the affine specification to illustrate the corollary, but the variance swap rate only depends on the risk-neutral drift of the instantaneous variance rate $\mu(v)$ under any variance rate dynamics:

$$
\operatorname{VS}_{t}(T)=\frac{1}{\tau} \mathbb{E}_{t}^{\mathbb{Q}}\left[\int_{t}^{T} v_{s} d s\right]=\frac{1}{\tau} \mathbb{E}_{t}^{\mathbb{Q}}\left[\int_{t}^{T} \mu\left(v_{s}\right) d s\right],
$$

as the expectation of the martingale component equals 0 . This conclusion is a result of the linear relation between the variance swap rate and future instantaneous variance rates. It is also this linear relation that makes variance swap contracts the most direct instruments for spanning variance risks.

\section{B. Model Design}

Proposition 1 identifies a set of conditions that generate the affine stochastic variance class. Based on these conditions, we design both a 1-factor and a 2-factor model for the variance risk dynamics and compare their empirical performance in matching the time-series and term structure behaviors of variance swap rates.

\section{A One-Factor Variance Rate Model}

In the 1-factor setting, we let the variance rate follow the square-root dynamics as in Heston (1993). Under the risk-neutral measure $\mathbb{Q}$, the instantaneous variance rate dynamics are

$$
d v_{t}=\kappa_{v}\left(\theta_{v}-v_{t}\right) d t+\sigma_{v} \sqrt{v_{t}} d B_{t}^{v} .
$$

Comparing equation (9) to the general conditions in equation (3), we have $b_{v}=$ $1, c_{v}=0, \alpha=0, \beta=\sigma_{v}^{2}, \lambda=0$. Plugging these parameterizations into equation (7), we have the variance swap rate as

$$
\operatorname{VS}_{t}(T)=\phi_{v}(\tau) v_{t}+\left(1-\phi_{v}(\tau)\right) \theta_{v}
$$

with $\phi_{v}(\tau)=\left(1-e^{-\kappa_{v} \tau}\right) /\left(\kappa_{v} \tau\right)$. With stationary risk-neutral variance rate dynamics $\left(\kappa_{v}>0\right)$, the coefficient $\phi_{v}(\tau)$ is between 0 and 1, and the variance swap 
rate is a weighted average of the instantaneous variance rate $v_{t}$ and its risk-neutral long-run mean $\theta_{v}$. The weight depends on the time to maturity $(\tau)$ of the swap contract and the risk-neutral mean-reversion speed of the variance rate $\left(\kappa_{v}\right)$. The linear 1-factor structure also implies the same statistical persistence for variance swap rates of all maturities.

Holding a fixed risk-neutral mean-reversion speed $\kappa_{v}>0$, the coefficient $\phi_{v}(\tau)$ starts at 1 at $\tau=0$ and declines to 0 with increasing maturity. Hence, the variance swap rate converges to the instantaneous variance rate as the maturity goes to 0 and converges to the risk-neutral long-run mean as the maturity goes to infinity. Holding the maturity fixed, as $\kappa_{v}$ declines, the risk-neutral dynamics of the instantaneous variance rate become more persistent, $\phi_{v}(\tau)$ increases, and the current variance rate $v_{t}$ has a larger impact on the variance swap rate of longer maturities.

Taking expectations on both sides of equation (10) under the statistical measure $\mathbb{P}$, we obtain the mean term structure of variance swap rates as

$$
\mathbb{E}^{\mathbb{P}}\left[\operatorname{VS}_{t}(T)\right]=\phi_{v}(\tau) \theta_{v}^{\mathbb{P}}+\left(1-\phi_{v}(\tau)\right) \theta_{v},
$$

which is a weighted average of the statistical mean $\theta_{v}^{\mathbb{P}} \equiv \mathbb{E}^{\mathbb{P}}\left[v_{t}\right]$ and the riskneutral mean $\theta_{v}$ of the instantaneous variance rate. Since $\phi_{v}(\tau)$ declines monotonically with increasing maturity, the risk-neutral mean has increasing weights at longer maturities. Therefore, to generate an upward- or downward-sloping mean term structure for the variance swap rates, we need the statistical mean and the risk-neutral mean of the instantaneous variance rate to be different. The difference between the 2 mean values dictates the sign and magnitude of the variance risk premium.

\section{A Two-Factor Variance Rate Model}

We consider 2-factor variance risk dynamics controlled by the following stochastic differential equations under the risk-neutral measure $\mathbb{Q}$ :

$$
\begin{aligned}
d v_{t} & =\kappa_{v}\left(m_{t}-v_{t}\right) d t+\sigma_{v} \sqrt{v_{t}} d B_{t}^{v}, \\
d m_{t} & =\kappa_{m}\left(\theta_{m}-m_{t}\right) d t+\sigma_{m} \sqrt{m_{t}} d B_{t}^{m}, \quad d B_{t}^{v} d B_{t}^{m}=0,
\end{aligned}
$$

where the instantaneous variance rate $\left(v_{t}\right)$ reverts to a stochastic mean level $\left(m_{t}\right)$. The mean level follows another square-root process. Analogous to Balduzzi, Das, and Foresi (1998) for interest rate modeling, we label $m_{t}$ as the stochastic central tendency of the instantaneous variance rate, with $\theta_{m}$ being the unconditional longrun mean for both $v_{t}$ and $m_{t}$ under the risk-neutral measure. Under the 2-factor variance risk specification, the variance swap rates are given by

$$
\operatorname{VS}_{t}(T)=\phi_{v}(\tau) v_{t}+\phi_{m}(\tau) m_{t}+\left(1-\phi_{v}(\tau)-\phi_{m}(\tau)\right) \theta_{m},
$$

with

$$
\begin{aligned}
\phi_{v}(\tau) & =\frac{1-e^{-\kappa_{v} \tau}}{\kappa_{v} \tau}, \\
\phi_{m}(\tau) & =\frac{1+\frac{\kappa_{m}}{\kappa_{v}-\kappa_{m}} e^{-\kappa_{v} \tau}-\frac{\kappa_{v}}{\kappa_{v}-\kappa_{m}} e^{-\kappa_{m} \tau}}{\kappa_{m} \tau} .
\end{aligned}
$$


The variance swap rate in equation (13) is a weighted average of the instantaneous variance rate $v_{t}$, its stochastic central tendency $m_{t}$, and the risk-neutral long-run mean $\theta_{m}$. The weight on the instantaneous variance rate is the same as in the 1 factor case. The weight converges to 1 as the maturity goes to 0 and converges to 0 as the maturity goes to infinity. The weight on $m_{t}$ also converges to 0 as the maturity goes to infinity. Hence, the variance swap rate starts at the instantaneous variance rate at 0 maturity and converges to the risk-neutral long-run mean $\theta_{m}$ as maturity goes to infinity. The stochastic central tendency factor plays a role at intermediate maturities, with the weighting coefficient $\phi_{m}(\tau)$ showing a humpshaped term structure.

Under this 2-factor structure, swap rates at different maturities can show different degrees of persistence. The central tendency factor is usually more persistent than the instantaneous variance rate, in which case the short-term swap rate is less persistent than the long-term swap rate.

\section{Market Prices of Variance Risks}

For both models, we assume that the market price on each source of risk is proportional to the square root of the risk level:

$$
\gamma\left(B_{t}^{v}\right)=\gamma^{v} \sqrt{v_{t}}, \quad \gamma\left(B_{t}^{m}\right)=\gamma^{m} \sqrt{m_{t}} .
$$

Under the 1-factor model, the statistical dynamics of the variance rate become

$$
d v_{t}=\kappa_{v}^{\mathbb{P}}\left(\theta_{v}^{\mathbb{P}}-v_{t}\right) d t+\sigma_{v} \sqrt{v_{t}} d B_{t}^{v},
$$

with $\kappa_{v}^{\mathbb{P}}=\left(\kappa_{v}-\gamma^{v} \sigma_{v}\right)$ and $\theta_{v}^{\mathbb{P}}=\kappa_{v} \theta_{v} / \kappa_{v}^{\mathbb{P}}$. Thus, a negative market price of variance risk makes the statistical variance rate process more mean reverting than its riskneutral counterpart $\left(\kappa_{v}^{\mathbb{P}}>\kappa_{v}\right)$ and makes the statistical mean variance rate lower than its risk-neutral counterpart $\left(\theta_{v}^{\mathbb{P}}<\theta_{v}\right)$.

Under the 2-factor model, the statistical dynamics of the variance rate become

$$
\begin{aligned}
& d v_{t}=\kappa_{v}^{\mathbb{P}}\left(\frac{\kappa_{v}}{\kappa_{v}^{\mathbb{P}}} m_{t}-v_{t}\right) d t+\sigma_{v} \sqrt{v_{t}} d B_{t}^{v}, \\
& d m_{t}=\kappa_{m}^{\mathbb{P}}\left(\theta_{m}^{\mathbb{P}}-m_{t}\right) d t+\sigma_{m} \sqrt{m_{t}} d B_{t}^{m},
\end{aligned}
$$

with $\kappa_{m}^{\mathbb{P}}=\kappa_{m}-\gamma^{m} \sigma_{m}$ and $\theta_{m}^{\mathbb{P}}=\kappa_{m} \theta_{m} / \kappa_{m}^{\mathbb{P}}$. In this case, the long-run statistical mean of the variance rate becomes $\theta_{v}^{\mathbb{P}}=\kappa_{v} \theta_{m}^{\mathbb{P}} / \kappa_{v}^{\mathbb{P}}=\kappa_{v} \kappa_{m} \theta_{m} /\left(\kappa_{v}^{\mathbb{P}} \kappa_{m}^{\mathbb{P}}\right)$. Similar to the 1-factor case, negative market price of variance risk $\left(\gamma^{\nu}\right)$ increases the meanreversion speed $\left(\kappa_{v}^{\mathbb{P}}\right)$ and reduces the long-run mean $\left(\theta_{v}^{\mathbb{P}}\right)$ under the statistical measure. A negative market price of the central tendency risk $\left(\gamma^{m}\right)$ has similar effects on the central tendency dynamics and further reduces the long-run statistical mean of the instantaneous variance rate.

\section{Estimating Variance Swap Term Structure Models}

We estimate the variance risk dynamics using over-the-counter quotes on term structure of variance swap rates on the S\&P 500 index. From a major broker 
dealer, we obtain daily closing quotes on variance swap rates with fixed times to maturity at 2, 3, 6, 12, and 24 months, starting January 10, 1996, and ending March 30, 2007, spanning more than 11 years. To avoid the effect of weekday patterns on the dynamics estimation, we sample the data weekly on every Wednesday. When Wednesday is a holiday, we use the quotes from the previous business day. The data contain 586 weekly observations for each series.

To sharpen the variance risk premium identification, we also compute the annualized realized return variance over different horizons based on daily log returns on the S\&P 500 index,

$$
\mathrm{RV}_{t, T}=\frac{365}{D} \sum_{d=1}^{D}\left(\ln \left[S_{t+d} / S_{t+d-1}\right]\right)^{2}
$$

where $S_{t}$ denotes the index level at time $t$ and $D$ denotes the number of days between time $t$ and $T$. Following industry standard in variance swap payoff calculations, we compute the realized variance using undemeaned log daily returns. At each date $t$, we compute realized variance over fixed horizons of 7, 30, 60, 90, 120 , and 150 days, and use these realized variance series together with the variance swap rates to identify the variance risk dynamics and variance risk premium.

\section{A. Summary Statistics of Variance Swap Rates}

Figure 1 plots in Graph A the time series of variance swap rates at 3 selected maturities of 2 (solid line), 6 (dashed line), and 24 (dotted line) months. Per industry convention, we represent the variance swap rates in volatility percentage points. The time-series plots show that the variance swap rates started at relatively low levels but experienced a spike during the 1997 Asian crisis, and another even larger spike during the hedge fund crisis in late 1998. The series witnessed another

\section{FIGURE 1}

Time Series and Term Structure of the Variance Swap Rates

Graph A of Figure 1 plots the time series of the variance swap rates in volatility percentage points at 3 selected times to maturity: 2 months (solid line), 6 months (dashed line), and 24 months (dotted line). Graph B plots representative variance swap rate term structures at different dates.

Graph A. Variance Swap Time Series

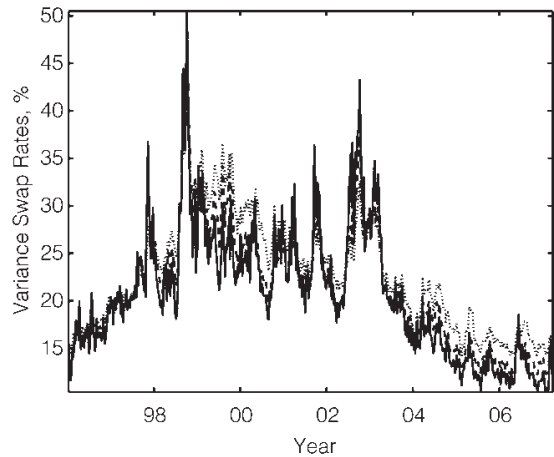

Graph B. Variance Swap Term Structure

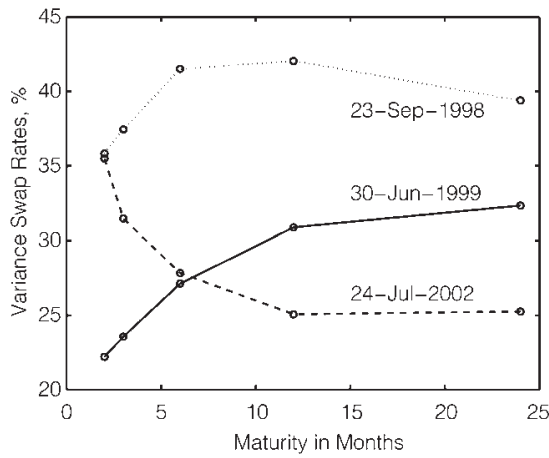


2 spikes between 2001 and 2003, but otherwise has been declining to very low levels. Over the course of the sample period, the variance swap rate level has varied greatly, from $10.39 \%$ to $50.48 \%$.

Graph B of Figure 1 plots the representative variance swap term structure at different dates. The graph shows that the term structure of variance swap rates can take a wide variety of shapes at different times, including upward-sloping, downward-sloping, and hump-shaped term structures. A successful model of variance risk dynamics must capture not only the large variation in the volatility levels, but also the different shapes of the term structure.

Table 1 reports the summary statistics of the variance swap rates across different maturities. The mean variance swap rates increase with maturity from $20.804 \%$ at 2-month maturity to $22.866 \%$ at 2-year maturity, thus generating an upward-sloping mean term structure. The standard deviation estimates decline as maturity increases. The variance swap rates show positive skewness but mild kurtosis. The weekly autocorrelation estimates are high and increasing with swap maturities. According to the theoretical analysis in the previous section, the upward-sloping mean term structure is evidence for nonzero market price of variance risk, the downward-sloping standard deviation term structure is evidence for mean reversion in the variance rate dynamics, and the upward-sloping autocorrelation term structure points to the existence of multiple variance risk factors.

TABLE 1

Summary Statistics of Variance Swap Rates

\begin{tabular}{|c|c|c|c|c|c|}
\hline Maturity & Mean & Std & Skew & Kurt & Auto \\
\hline 2 & 20.804 & 6.779 & 0.787 & 0.794 & 0.945 \\
\hline 3 & 20.892 & 6.495 & 0.716 & 0.672 & 0.961 \\
\hline 6 & 21.489 & 6.301 & 0.745 & 0.863 & 0.972 \\
\hline 12 & 22.258 & 6.061 & 0.607 & 0.164 & 0.979 \\
\hline 24 & 22.866 & 5.909 & 0.556 & -0.218 & 0.983 \\
\hline
\end{tabular}

\section{B. Estimation Methodology}

To estimate the variance risk dynamics, we cast the model into a state-space form and extract the variance risk factors $\left(v_{t}\right.$ and $\left.m_{t}\right)$ from the observed variance swap rates using the classic Kalman (1960) filter. We build the state propagation equation based on the statistical dynamics of the variance rates. Under the 2-factor model, we set $X_{t}=\left[v_{t}, m_{t}\right]^{\top}$ and construct the state propagation equation based on the Euler approximation of the statistical dynamics in equation (17),

$$
X_{t}=A+\Phi X_{t-1}+\Sigma\left(X_{t-1}\right) \sqrt{\Delta t} \varepsilon_{t}
$$

with $\varepsilon$ denoting a 2-dimensional independent and identically distributed (i.i.d.) standard normal innovation vector, 


$$
\begin{aligned}
& A=(I-\Phi) \theta^{\mathbb{P}}, \quad \Phi=e^{-\kappa^{\mathbb{P}} \Delta t}, \\
& \theta^{\mathbb{P}}=\left[\begin{array}{c}
\theta_{v}^{\mathbb{P}} \\
\theta_{m}^{\mathbb{P}}
\end{array}\right], \quad \kappa^{\mathbb{P}}=\left[\begin{array}{cc}
\kappa_{v}^{\mathbb{P}} & -\kappa_{v} \\
0 & \kappa_{m}^{\mathbb{P}}
\end{array}\right], \\
& \Sigma\left(X_{t-1}\right)=\left[\begin{array}{cc}
\sigma_{v} \sqrt{v_{t-1}} & 0 \\
0 & \sigma_{m} \sqrt{m_{t-1}}
\end{array}\right],
\end{aligned}
$$

and $\Delta t=7 / 365$ being the weekly time interval of the discretization. The 1-dimensional state propagation equation for the 1-factor model is defined analogously.

We construct the measurement equation based on the observed variance swap rates:

$$
y_{t}=\operatorname{VS}_{t}\left(T, X_{t}\right)+e_{t}, \quad T-t=2,3,6,12,24 \text { months, }
$$

where $y_{t}$ denotes the observed variance swap series, $\operatorname{VS}_{t}\left(T, X_{t}\right)$ denotes their corresponding model values as a function of the variance risk factors $X_{t}$, and $e_{t}$ denotes the measurement error. We assume that the measurement error is independent of the state vector and that the measurement error on each of the 5 series is mutually independent but with distinct variance.

Since the state propagation equation is Gaussian linear and the measurement equation is linear in the state vector, the Kalman filter provides efficient forecasts and updates on the state vector and the observed variance swap rates. We build the likelihood on the variance swap rates based on the forecasting errors from the Kalman filter. Specifically, let $\left(\bar{y}_{t}, \bar{Q}_{t}\right)$ denote the time- $(t-1)$ Kalman filter forecasts on the conditional mean and conditional variance of the variance swap rates at time $t$; then the time- $(t-1)$ conditional log likelihood on the variance swap rates at time $t$ is

$$
l_{t-1}\left(y_{t}, \Theta\right)=-\frac{1}{2}\left[\log \left|\bar{Q}_{t}\right|+\left(\left(y_{t}-\bar{y}_{t}\right)^{\top}\left(\bar{Q}_{t}\right)^{-1}\left(y_{t}-\bar{y}_{t}\right)\right)\right],
$$

where $\Theta$ denotes the set of model parameters.

Furthermore, given the variance risk factors $\left(X_{t}\right)$ extracted from the Kalman filter, we can predict the annualized realized variance based on the statistical dynamics of the risk factors,

$$
\mathbb{E}_{t}^{\mathbb{P}}\left[\mathrm{RV}_{t, T}\right]=\frac{1}{\tau}\left[\left(\mathbf{B}(\tau)^{\mathbb{P}}\right)^{\top} X_{t}+C(\tau)^{\mathbb{P}}\right]
$$

where the coefficients are analogous to those defined in Proposition 2,

$$
\begin{aligned}
& \mathbf{B}(\tau)^{\mathbb{P}}=\left(I-e^{-\left(\kappa^{\mathbb{P}}\right)^{\top} \tau}\right)\left(\left(\kappa^{\mathbb{P}}\right)^{\top}\right)^{-1} \mathbf{b}_{v}, \\
& C(\tau)^{\mathbb{P}}=\left(c_{v}+\mathbf{b}_{v}^{\top} \theta^{\mathbb{P}}\right) \tau-\left(\mathbf{B}(\tau)^{\mathbb{P}}\right)^{\top} \theta^{\mathbb{P}} .
\end{aligned}
$$

Under the 2-factor model, we have $\mathbf{b}_{v}=[1,0]^{\top}$ and $c_{v}=0$. Under the 1-factor model, we have $\mathbf{b}_{v}=1, c_{v}=0, \theta^{\mathbb{P}}=\theta_{v}^{\mathbb{P}}$, and $\kappa^{\mathbb{P}}=\kappa_{v}^{\mathbb{P}}$.

Given the variance forecasts, we build the likelihood function on the realized variances assuming that the forecasting errors on the realized variance, 
$e_{t+D}^{\mathrm{RV}}=\mathrm{RV}_{t, t+D}-\mathbb{E}_{t}^{\mathbb{P}}\left[\mathrm{RV}_{t, t+D}\right]$ with $D=7,30,60,90,120,150$ days, are normally distributed with constant covariance matrix $Q_{\mathrm{RV}}$. Thus, the time- $t$ conditional log likelihood on the realized variance becomes

$$
l_{t}\left(e_{t+D}^{\mathrm{RV}}, \Theta\right)=-\frac{1}{2}\left[\log \left|Q_{\mathrm{RV}}\right|+\left(e_{t+D}^{\mathrm{RV}}\right)^{\top}\left(Q_{\mathrm{RV}}\right)^{-1}\left(e_{t+D}^{\mathrm{RV}}\right)\right] .
$$

For estimation, we assume that the forecasting errors on variance swaps and realized variances are independent but with distinct variance. Thus, the aggregate $\log$ likelihood becomes the summation of the log likelihood values on the 2 sets of data series. We numerically maximize the aggregate log likelihood value to estimate the model parameters.

\section{Model Performance}

Table 2 reports the summary statistics of the pricing errors, defined as the difference between the variance swap quotes and the model-implied values, both in volatility percentage points. We report the mean error (Mean), root mean squared error (RMSE), weekly autocorrelation (Auto), and maximum absolute pricing error (Max). The last column $\left(R^{2}\right)$ in each panel reports the explained variation, defined as 1 minus the ratio of the pricing error variance to the variance of the original swap series. The last row of Table 2 reports the maximized log likelihood values.

\section{TABLE 2}

\section{Summary Statistics of the Pricing Errors on the Variance Swap Rates}

Entries report the summary statistics of the model pricing errors on the variance swap rates, including the sample average (Mean), root mean squared error (RMSE), weekly autocorrelation (Auto), maximum absolute error (Max), and explained percentage variation $\left(R^{2}\right)$, defined as 1 minus the variance of the pricing error to the variance of the original swap rate quotes. The pricing errors are defined as the difference between the variance swap rate quotes and the corresponding model-implied values, both in volatility percentage points. The last row reports the maximized log likelihood values for the 2 models.

\begin{tabular}{|c|c|c|c|c|c|c|c|c|c|c|}
\hline \multirow[b]{2}{*}{ Maturity } & \multicolumn{5}{|c|}{$\begin{array}{l}\text { Panel A. One-Factor } \\
\text { Variance Risk Model }\end{array}$} & \multicolumn{5}{|c|}{$\begin{array}{l}\text { Panel B. Two-Factor } \\
\text { Variance Risk Model }\end{array}$} \\
\hline & Mean & RMSE & Auto & Max & $R^{2}$ & Mean & RMSE & Auto & Max & $R^{2}$ \\
\hline 2 & -0.15 & 1.77 & 0.82 & 7.86 & 93.19 & 0.27 & 0.80 & 0.62 & 4.20 & 98.77 \\
\hline 3 & -0.20 & 1.13 & 0.89 & 4.49 & 97.05 & -0.00 & 0.00 & 0.35 & 0.01 & 100.00 \\
\hline 6 & 0.00 & 0.00 & 0.44 & 0.00 & 100.00 & -0.09 & 0.40 & 0.75 & 2.59 & 99.61 \\
\hline 12 & 0.04 & 1.08 & 0.90 & 3.88 & 96.82 & 0.00 & 0.00 & 0.18 & 0.00 & 100.00 \\
\hline 24 & -0.60 & 1.77 & 0.95 & 5.05 & 92.01 & -0.05 & 0.49 & 0.68 & 3.39 & 99.32 \\
\hline Average & -0.18 & 1.15 & 0.80 & 4.25 & 95.81 & 0.03 & 0.34 & 0.52 & 2.04 & 99.54 \\
\hline Likelihood & \multicolumn{5}{|c|}{$-5,793.4$} & \multicolumn{5}{|c|}{$-3,318.4$} \\
\hline
\end{tabular}

The 1-factor model fits the 6-month variance swap to near perfection, but the pricing errors increase at other maturities. The performance of the 2-factor model is more uniform across different maturities. The explained variations range from $98.77 \%$ to $100.00 \%$. The root mean squared pricing errors range from practically 0 to 0.8 volatility percentage points, no larger than the average bid-ask spreads for the over-the-counter variance swap rate quotes. ${ }^{1}$ The 2 -factor model

\footnotetext{
${ }^{1}$ The bid-ask spreads on variance swap rate quotes from major broker dealers average around half to 1 volatility percentage point for the S\&P 500 index.
} 
also performs significantly better than the 1-factor model in terms of the log likelihood values. A formal likelihood ratio test rejects the 1-factor model over any reasonable confidence level.

\section{Variance Risk Dynamics and the Term Structure of Variance Swap Rates}

Exploiting the information in the time series and term structure of variance swap rates and the realized variance, we can accurately identify the variance risk dynamics under both the statistical and the risk-neutral measures. Table 3 reports the parameter estimates and the absolute magnitudes of the $t$-statistics in parentheses. Focusing on the 2-factor model specification, we observe that the risk-neutral mean-reversion speed for the instantaneous variance rate $\left(\kappa_{v}=4.373\right)$ is much higher than that for the central tendency risk factor $\left(\kappa_{m}=0.1022\right)$. To gain more intuition, we define the half-life $H$ of a first-order autoregressive process as the number of weeks for the autocorrelation of the process to decay to half of its weekly autocorrelation level, $H=\ln (\phi / 2) / \ln (\phi)$, with $\phi=\exp (-\kappa \Delta t), \Delta t=7 / 365$ denoting the weekly autocorrelation of a series. Under the risk-neutral measure, the mean-reversion speed estimates imply a half-life of less than 10 weeks for the instantaneous variance rate $v_{t}$, but almost 7 years for the central tendency factor $m_{t}$.

\section{TABLE 3}

\section{Parameter Estimates of Affine Stochastic Variance Models}

Entries report the maximum likelihood parameter estimates and the absolute magnitudes of $t$-values (in parentheses) of the 1-factor (Panel A of Table 3) and the 2-factor (Panel B) affine stochastic variance models. The estimation employs weekly data on variance swap rates at maturities of $2,3,6,12$, and 24 months and ex post realized variances at maturities of 7 , $30,60,90$, and 150 days. The sample is from January 10, 1996 to March 28, 2007 (586 observations for each series).

\begin{tabular}{|c|c|c|c|c|c|c|}
\hline$\underline{X_{t}}$ & $\kappa$ & $\theta$ & $\sigma$ & $\gamma$ & $\kappa^{\mathbb{P}}$ & $\theta^{\mathbb{P}}$ \\
\hline \multicolumn{7}{|c|}{ Panel A. One-Factor Variance Risk Model } \\
\hline$v_{t}$ & $\begin{array}{c}0.1547 \\
(13.81)\end{array}$ & $\begin{array}{c}0.1220 \\
(32.55)\end{array}$ & $\begin{array}{l}0.2550 \\
(47.47)\end{array}$ & $\begin{array}{c}-17.0141 \\
(43.06)\end{array}$ & $\begin{array}{c}4.4929 \\
(71.42)\end{array}$ & $\begin{array}{c}0.0042 \\
(21.52)\end{array}$ \\
\hline \multicolumn{7}{|c|}{ Panel B. Two-Factor Variance Risk Model } \\
\hline$v_{t}$ & $\begin{array}{c}4.3730 \\
(38.72)\end{array}$ & - & $\begin{array}{c}0.4221 \\
(44.10)\end{array}$ & $\begin{array}{c}-16.3746 \\
(37.70)\end{array}$ & $\begin{array}{l}11.2851 \\
(51.96)\end{array}$ & $\begin{array}{l}0.0158 \\
(3.71)\end{array}$ \\
\hline$m_{t}$ & $\begin{array}{l}0.1022 \\
(9.30)\end{array}$ & $\begin{array}{c}0.0838 \\
(24.31)\end{array}$ & $\begin{array}{c}0.1581 \\
(47.64)\end{array}$ & $\begin{array}{c}-0.6844 \\
(1.84)\end{array}$ & $\begin{array}{l}0.2104 \\
(3.40)\end{array}$ & $\begin{array}{c}0.0407 \\
(3.68)\end{array}$ \\
\hline
\end{tabular}

The different risk-neutral persistence dictates that the 2 risk factors have different impacts across the term structure of the variance swap rates. We can convert the risk-neutral persistence estimates into factor loading coefficients $\phi_{v}(\tau)$ and $\phi_{m}(\tau)$ as in equation (14):

$$
\begin{aligned}
\phi_{v}(\tau) & =\frac{1-e^{-\kappa_{v} \tau}}{\kappa_{v} \tau}, \\
\phi_{m}(\tau) & =\frac{1+\frac{\kappa_{m}}{\kappa_{v}-\kappa_{m}} e^{-\kappa_{v} \tau}-\frac{\kappa_{v}}{\kappa_{v}-\kappa_{m}} e^{-\kappa_{m} \tau}}{\kappa_{m} \tau},
\end{aligned}
$$


with which the variance swap rates of different maturities are linked to the 2 risk factors:

$$
\operatorname{VS}_{t}(T)=\phi_{v}(\tau) v_{t}+\phi_{m}(\tau) m_{t}+\left(1-\phi_{v}(\tau)-\phi_{m}(\tau)\right) \theta_{m}
$$

The loading coefficients measure the contemporaneous responses of the variance swap term structure to unit shocks in the 2 variance risk factors $v_{t}$ and $m_{t}$. Figure 2 plots the term structure of the 2 responses in Graph A, with the solid line denoting the response to $v_{t}$ and the dashed line denoting the response to $m_{t}$. The dash-dotted line captures the remaining weight on the risk-neutral mean $\left(\theta_{m}\right)$ of the variance rate and the central tendency. The impact of the transient variance rate factor $\left(v_{t}\right)$ is mainly at short maturities. Its impact declines as maturity increases. On the other hand, the contribution of the persistent central tendency factor $\left(m_{t}\right)$ starts at 0 but increases progressively as the variance swap maturity increases. The remaining weight on the risk-neutral mean also starts at 0 and increases monotonically with increasing maturity. This increasing weight on a constant is responsible in generating a downward-sloping term structure on the standard deviation of the variance swap rate, observed in Table 1.

\section{FIGURE 2}

\section{Factor Loadings and the Mean Term Structure of Variance Swap Rates}

Graph A of Figure 2 plots the contemporaneous response of the variance swap term structure to unit shocks on the instantaneous variance rate $v_{t}$ (solid line) and the central tendency factor $m_{t}$ (dashed line). The dash-dotted line represents the remaining loading on the common unconditional risk-neutral mean $\left(\theta_{m}\right)$ of the variance rate and the central tendency. Graph B plots the mean term structure of the variance swap rate in volatility percentage points. The circles are sample averages of the data, and the solid line represents values computed from the estimated 2 -factor variance risk model.

Graph A. Factor Loading

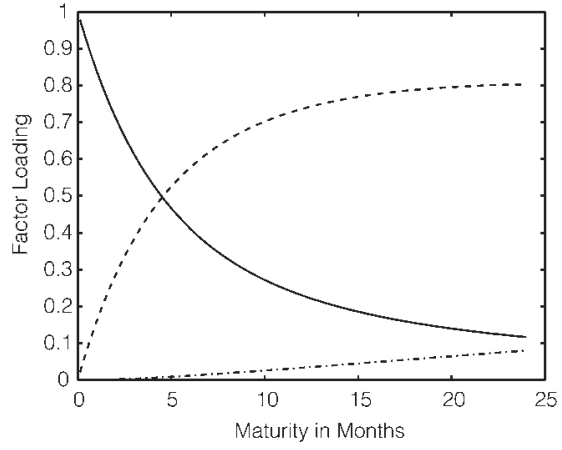

Graph B. Mean Variance Swap Term Structure

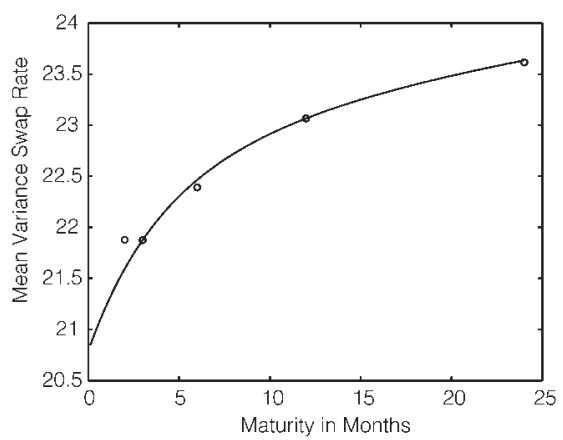

Graph B of Figure 2 plots the mean variance swap term structure. The 5 circles represent the sample averages of the 5 data series, and the solid lines are computed from the estimated 2-factor variance risk model. The upward-sloping mean term structure is consistent with the negative market price estimates $(\gamma)$ on the variance risks in Table 3. The market price of the instantaneous variance rate is strongly negative; the market price of the central tendency factor is also negative, but with smaller absolute magnitude. The negative market prices on the 2 risk factors make the statistical mean-reversion speeds $\left(\kappa^{\mathbb{P}}\right)$ larger and the statistical long-run means $\left(\theta^{\mathbb{P}}\right)$ lower than their risk-neutral counterparts. The 3 long-run means show the following ranking: $\theta_{v}^{\mathbb{P}}<\theta_{m}^{\mathbb{P}}<\theta_{m}$. The statistical mean of the 
variance rate is lower than the statistical mean of the central tendency factor. Both are lower than their common risk-neutral mean $\theta_{m}$.

Taking unconditional expectations on both sides of equation (13) under the statistical measure $\mathbb{P}$, we obtain the mean term structure of variance swap rates as

$$
\mathbb{E}^{\mathbb{P}}\left[\operatorname{VS}_{t}(T)\right]=\phi_{v}(\tau) \theta_{v}^{\mathbb{P}}+\phi_{m}(\tau) \theta_{m}^{\mathbb{P}}+\left(1-\phi_{v}(\tau)-\phi_{m}(\tau)\right) \theta_{m},
$$

which is a weighted average of the statistical mean of the instantaneous variance rate $\theta_{v}^{\mathbb{P}}$, the statistical mean of the central tendency factor $\theta_{m}^{\mathbb{P}}$, and the common risk-neutral mean of the variance rate and the central tendency $\theta_{m}$. The factor loading in Graph A of Figure 2 suggests that $\theta_{v}^{\mathbb{P}}$ has the highest weighting at short maturities, whereas both $\theta_{m}^{\mathbb{P}}$ and $\theta_{m}$ have increasing weights as the swap maturity increases. The factor loadings and the ranking of the 3 long-run mean values generate the upward-sloping mean term structure shown in Graph B of Figure 2.

The 2-factor variance risk structure also generates different statistical persistence for swap rates at different maturities. Table 3 shows that the statistical mean-reversion speed for the instantaneous variance rate is much larger than that for the central tendency factor. The statistical half-life of the instantaneous variance rate is just about 4 weeks, whereas the statistical half-life of the central tendency factor is over 3 years. The increasing weight on the central tendency factor for longer maturity swaps suggests that the variance swap rate becomes increasingly persistent as the swap maturity increases. This observation is consistent with the weekly autocorrelation estimates reported in Table 1.

\section{E. Model Stability and Out-of-Sample Performance}

To gauge the stability of the 2-factor variance risk model and its out-ofsample performance, we divide the data into 2 subsample periods. The 1 st subsample is from January 10, 1996 to June 27, 2001, 286 weekly observations for each series. The 2nd subsample is the remaining sample period from July 4, 2001 to March 28, 2007, 300 weekly observations for each series. Each sample contains about 5.5 years of data.

We repeat the model estimation on the 2 subsamples. Table 4 reports the subsample model parameter estimates. The estimates are largely in line with the whole-sample estimates. Comparing the parameter estimates during the 2 subsamples, we observe that the risk-neutral mean-reversion speed for the instantaneous variance rate is smaller during the 1 st subsample than during the 2 nd subsample. The opposite is true for the central tendency factor, as the estimate for its mean-reversion speed is no longer significantly different from 0 during the 2 nd subsample. The different estimates suggest that the roles of the 2 risk factors become more separated during the 2 nd subsample. The impacts of the instantaneous variance rate are mainly at short maturities and die out quickly as the maturity increases. The impacts of the central tendency factor become even more persistent across the variance swap term structure. On the other hand, the market price estimates are relatively stable over the 2 sample periods.

To gauge the out-of-sample pricing performance of the 2-factor variance risk model, we use the parameters estimated from the 1st subsample to price 
TABLE 4

Subsample Parameter Estimates of the 2-Factor Variance Risk Model

Entries report the maximum likelihood parameter estimates and the absolute magnitudes of $t$-values (in parentheses) of the 2 -factor variance risk model over 2 subsample periods. The 1st subsample (Panel A of Table 4) is from January 10,1996 to June 27, 2001, 286 weekly observation for each series. The 2nd subsample (Panel B) is from July 4, 2001 to March 28 , 2007, 300 weekly observations for each series. The estimation employs weekly data on variance swap rates at maturities of $2,3,6,12$, and 24 months and ex post realized variances at maturities of $7,30,60$, 90, and 150 days.

\begin{tabular}{|c|c|c|c|c|c|c|}
\hline$\underline{X_{t}}$ & $\kappa$ & $\theta$ & $\sigma$ & $\gamma$ & $\kappa^{\mathbb{P}}$ & $\theta^{\mathbb{P}}$ \\
\hline \multicolumn{7}{|c|}{ Panel A. Subsample Period: 1996-2001 } \\
\hline$v_{t}$ & $\begin{array}{c}3.3945 \\
(16.53)\end{array}$ & - & $\begin{array}{l}0.4635 \\
(27.27)\end{array}$ & $\begin{array}{c}-16.2472 \\
(25.12)\end{array}$ & $\begin{array}{l}10.9250 \\
(29.84)\end{array}$ & $\begin{array}{l}0.0153 \\
(3.88)\end{array}$ \\
\hline$m_{t}$ & $\begin{array}{l}0.1857 \\
(7.61)\end{array}$ & $\begin{array}{c}0.0715 \\
(15.14)\end{array}$ & $\begin{array}{c}0.2086 \\
(26.98)\end{array}$ & $\begin{array}{c}-0.4029 \\
(1.11)\end{array}$ & $\begin{array}{c}0.2697 \\
(3.17)\end{array}$ & $\begin{array}{l}0.0492 \\
(3.84)\end{array}$ \\
\hline \multicolumn{7}{|c|}{ Panel B. Subsample Period: 2001-2007 } \\
\hline$v_{t}$ & $\begin{array}{l}5.3789 \\
(33.83)\end{array}$ & - & $\begin{array}{c}0.3476 \\
(27.86)\end{array}$ & $\begin{array}{c}-15.6418 \\
(19.44)\end{array}$ & $\begin{array}{c}10.8160 \\
(33.91)\end{array}$ & $\begin{array}{l}0.0239 \\
(0.46)\end{array}$ \\
\hline$m_{t}$ & $\begin{array}{l}0.0010 \\
(0.06)\end{array}$ & $\begin{array}{l}4.2187 \\
(0.06)\end{array}$ & $\begin{array}{c}0.1058 \\
(24.42)\end{array}$ & $\begin{array}{c}-0.8444 \\
(0.46)\end{array}$ & $\begin{array}{l}0.0903 \\
(0.46)\end{array}$ & $\begin{array}{c}0.0480 \\
(0.46)\end{array}$ \\
\hline
\end{tabular}

the variance swap rates during the 2 nd subsample. Table 5 reports the summary statistics on the out-of-sample pricing errors. Compared with the in-sample pricing error statistics in Table 2, the out-of-sample errors are not much different. The average explained variation is $99.49 \%$ compared to the in-sample estimate of $99.54 \%$. These statistics show that the model generates stable performance over time.

TABLE 5

Out-of-Sample Pricing Performance of the 2-Factor Variance Risk Model

We estimate the model during the 1st subsample from January 10, 1996 to June 27, 2001, and use the model parameters to price variance swap rates out of sample from July 4, 2001 to March 28, 2007. The pricing errors are defined as the difference between the variance swap rate quotes and the corresponding model-implied values, both in volatility percentage points. Entries report the summary statistics of the model pricing errors on the variance swap rates, including the sample average (Mean), root mean squared error (RMSE), weekly autocorrelation (Auto), maximum absolute error (Max), and explained percentage variation $\left(R^{2}\right)$, defined as 1 minus the variance of the pricing error to the variance of the original swap rate quotes.

\begin{tabular}{|c|c|c|c|c|c|}
\hline Maturity & Mean & $\underline{\text { RMSE }}$ & Auto & Max & $R^{2}$ \\
\hline 2 & 0.20 & 0.64 & 0.56 & 2.68 & 99.23 \\
\hline 3 & -0.00 & 0.00 & 0.18 & 0.00 & 100.00 \\
\hline 6 & -0.03 & 0.20 & 0.73 & 0.65 & 99.87 \\
\hline 12 & 0.00 & 0.00 & 0.49 & 0.00 & 100.00 \\
\hline 24 & -0.21 & 0.60 & 0.89 & 2.39 & 98.33 \\
\hline Average & -0.01 & 0.29 & 0.57 & 1.14 & 99.49 \\
\hline
\end{tabular}

\section{Optimal Variance Swap Investment Decisions}

The availability of variance swap contracts makes it convenient for investors to either hedge away variance risk or achieve additional exposures in it and receive variance risk premium. How does this availability alter an investor's asset allocation decision? To answer this question, we study the optimal asset allocation problem for an investor who has access to the money market account, the 
stock index, and a series of return variance swaps on the index across different maturities.

We assume that investment in the money market generates a constant riskfree interest rate $r$, and that the stock index evolves under the statistical measure $\mathbb{P}$ as

$$
d S_{t} / S_{t}=\left(r+\gamma^{S} v_{t}\right) d t+\sqrt{v_{t}} d B_{t}^{S},
$$

where $B_{t}^{S}$ denotes a Brownian motion that measures the stock index return risk and $\gamma^{S} v_{t}$ denotes the instantaneous risk premium on the index return, which we assume is proportional to the instantaneous variance rate level.

We analyze the allocation problem under the 2-factor variance risk specification that we have estimated in the previous section. Under a 2-factor variance risk structure, the model values of the variance swap rates across all maturities are determined by 2 sources of variations. An investor can choose any 2 variance swap contracts of distinct maturities $\left(T_{1}\right.$ and $\left.T_{2}\right)$ to span the 2 sources of variance risk. The statistical evolution of the value of a variance swap contract with expiry date $T, \mathrm{VS}_{t}(T)$, is given by

$$
\begin{aligned}
d \mathrm{VS}_{t}(T)= & \left(\phi_{v}(T-t) \sigma_{v} \gamma^{v} v_{t}+\phi_{m}(T-t) \sigma_{m} \gamma^{m} m_{t}\right) d t \\
& +\phi_{v}(T-t) \sigma_{v} \sqrt{v_{t}} d B_{t}^{v}+\phi_{m}(T-t) \sigma_{m} \sqrt{m_{t}} d B_{t}^{m} .
\end{aligned}
$$

To capture the well-known leverage effect, we decompose the Brownian motion in the instantaneous variance rate dynamics into 2 components,

$$
d B_{t}^{v}=\rho d B_{t}^{S}+\sqrt{1-\rho^{2}} d B_{t}^{z}
$$

where $\rho$ measures the instantaneous correlation between the return risk and the variance risk and $B_{t}^{z}$ denotes the independent component of the variance risk. Assuming that the market price of the independent variance risk is also proportional to the square root of the instantaneous variance rate level, $\gamma\left(B_{t}^{z}\right)=\gamma^{z} \sqrt{v_{t}}$, we can decompose the instantaneous total variance risk premium into 2 components, one from the return risk and the other from the independent variance risk, $\gamma^{v} v_{t}=\rho \gamma^{S} v_{t}+\sqrt{1-\rho^{2}} \gamma^{z} v_{t}$

We assume that an investor allocates her initial wealth $W_{t}$ at time $t$ among the money market account, the stock index $S_{t}$, and 2 variance swap contracts of distinct expiry dates $T_{1}$ and $T_{2}$. Let $W_{t}^{S}$ and $W_{t}^{B}$ denote the amount of money invested in the stock index and the money market, respectively, and let $N_{1}$ and $N_{2}$ denote the dollar notional amount invested in the 2 variance swap contracts, respectively. The investor's budget constraint becomes

$$
W_{t}=W_{t}^{S}+W_{t}^{B}+N_{1}\left(\mathrm{VS}_{t}(T)-K_{1}\right)+N_{2}\left(\mathrm{VS}_{t}\left(T_{2}\right)-K_{2}\right),
$$

where $K_{1}$ and $K_{2}$ are the delivery prices of the 2 variance swap contracts. A negative notional amount implies a short position on the variance swap contract. We assume that at the time of decision making $t$, we initiate new variance swap contracts with the delivery price set to the prevailing variance swap rate: $K_{1}=\mathrm{VS}_{t}\left(T_{1}\right)$ and $K_{2}=\mathrm{VS}_{t}\left(T_{2}\right)$. In this case, the variance swap contracts have 0 initial values, and we have $W_{t}^{B}=W_{t}-W_{t}^{S}$. In reality, margin requirements and leverage constraints can limit the actual notional amount of variance swap contracts that an 
investor can sign on. We do not directly consider this and other financial market constraints in our optimization.

If we use share prices and wealth fractions instead of dollar amounts, we can write the wealth dynamics as

$$
\frac{d W_{t}}{W_{t}}=w_{t} \frac{d S_{t}}{S_{t}}+\left(1-w_{t}\right) r d t+n_{1 t} d \mathrm{VS}_{t}\left(T_{1}\right)+n_{2 t} d \mathrm{VS}_{t}\left(T_{2}\right),
$$

where $w_{t}$ denotes the fraction of wealth invested in the stock index and $\left(n_{1 t}, n_{2 t}\right)$ denote the fractions of wealth invested as notional invested in the 2 variance swap contracts.

The investor chooses the allocation weights to maximize her utility of wealth $W_{\mathcal{T}}$ at the terminal time $\mathcal{T} \leq \min \left(T_{1}, T_{2}\right)$. Assuming CRRA utility with relative risk aversion coefficient $\eta>0$, we can write the indirect utility function as

$$
J(t, W, v)=\sup _{\left(w_{t}, n_{1 t}, n_{2 t}\right)} \mathbb{E}\left(\frac{W_{\mathcal{T}}^{1-\eta}}{1-\eta} \mid W_{t}=W, v_{t}=v\right), \quad \eta \neq 1,
$$

subject to the budget constraint in equation (32).

We can solve the indirect utility function $J$ and the optimal allocation weights in analytical forms:

Proposition 3. Given the optimization problem in equation (33) under the budget constraint in equation (32), the stock index dynamics in equation (28), and the variance swap dynamics in equation (29), the indirect utility function has the analytical representation

$$
J(t, W, v)=\frac{W_{t}^{1-\eta}}{1-\eta} \exp \left(h_{v}(u) v_{t}+h_{m}(u) m_{t}+k(u)\right),
$$

with $u \equiv \mathcal{T}-t$ denoting the investment horizon and the coefficients solving the following ordinary differential equations:

$$
\begin{aligned}
h_{v}^{\prime}(u)= & \frac{1}{2 \eta} \sigma_{v}^{2} h_{v}(u)^{2}+\left(\frac{1-\eta}{\eta} \sigma_{v} \gamma^{v}-\kappa_{v}^{\mathbb{P}}\right) h_{v}(u) \\
& +\frac{1-\eta}{2 \eta}\left(\left(\gamma^{S}\right)^{2}+\left(\gamma^{z}\right)^{2}\right), \\
h_{m}^{\prime}(u)= & \frac{1}{2 \eta} \sigma_{m}^{2} h_{m}(u)^{2}+\kappa_{v} h_{v}(u)+\left(\frac{1-\eta}{\eta} \sigma_{m} \gamma^{m}-\kappa_{m}^{\mathbb{P}}\right) h_{m}(u) \\
& +\frac{1-\eta}{2 \eta}\left(\gamma^{m}\right)^{2}, \\
k^{\prime}(u)= & r(1-\eta)+\theta_{m}^{\mathbb{P}} \kappa_{m}^{\mathbb{P}} h_{m}(u),
\end{aligned}
$$

starting at $h_{v}(0)=h_{m}(0)=k(0)=0$. The optimal allocations to the stock index $\left(w_{t}\right)$ and the 2 variance swap contracts $\left(n_{1 t}, n_{2 t}\right)$ are

$$
w_{t}=\frac{1}{\eta}\left(\gamma^{S}-\frac{\rho}{\sqrt{1-\rho^{2}}} \gamma^{z}\right)
$$




$$
\begin{aligned}
n_{1 t}=\frac{1}{\eta D}[ & \left(\frac{\gamma^{z}}{\sigma_{v} \sqrt{1-\rho^{2}}}+h_{v}(u)\right) \phi_{m}\left(T_{2}-t\right) \\
& \left.-\left(\frac{\gamma^{m}}{\sigma_{m}}+h_{m}(u)\right) \phi_{v}\left(T_{2}-t\right)\right], \\
n_{2 t}=\frac{1}{\eta D}[ & -\left(\frac{\gamma^{z}}{\sigma_{v} \sqrt{1-\rho^{2}}}+h_{v}(u)\right) \phi_{m}\left(T_{1}-t\right) \\
& \left.+\left(\frac{\gamma^{m}}{\sigma_{m}}+h_{m}(u)\right) \phi_{v}\left(T_{1}-t\right)\right],
\end{aligned}
$$

with $D=\phi_{v}\left(T_{1}-t\right) \phi_{m}\left(T_{2}-t\right)-\phi_{v}\left(T_{2}-t\right) \phi_{m}\left(T_{1}-t\right)$.

For comparison, we also derive the optimal allocation decisions when the investor can only invest in the stock index alone or the 2 variance swap contracts alone:

Proposition 4. If the investor can only invest in the money market account and the stock index, the optimal fraction of wealth invested in the stock index is

$$
w_{t}=\frac{1}{\eta}\left(\gamma^{S}+\rho \sigma_{v} h(u)\right),
$$

where the intertemporal hedging demand coefficient $h(u)$ solves

$$
\begin{aligned}
h^{\prime}(u)= & \frac{\rho^{2}(1-\eta)+\eta}{2 \eta} \sigma_{v}^{2} h(u)^{2}+\left(\frac{1-\eta}{\eta} \sigma_{v} \rho \gamma^{S}-\kappa_{v}^{\mathbb{P}}\right) h_{v}(u) \\
& +\frac{1-\eta}{2 \eta}\left(\gamma^{S}\right)^{2},
\end{aligned}
$$

starting at $h(0)=0$. If the investor can only invest in the money market account and the variance swap contract, the optimal fractions of wealth invested as notional in the 2 variance swap contracts are

$$
\begin{aligned}
n_{1 t}=\frac{1}{\eta D}[ & \left(\frac{\gamma^{v}}{\sigma_{v}}+h_{v}(u)\right) \phi_{m}\left(T_{2}-t\right) \\
& \left.-\left(\frac{\gamma^{m}}{\sigma_{m}}+h_{m}(u)\right) \phi_{v}\left(T_{2}-t\right)\right], \\
n_{2 t}=\frac{1}{\eta D}[ & -\left(\frac{\gamma^{v}}{\sigma_{v}}+h_{v}(u)\right) \phi_{m}\left(T_{1}-t\right) \\
& \left.+\left(\frac{\gamma^{m}}{\sigma_{m}}+h_{m}(u)\right) \phi_{v}\left(T_{1}-t\right)\right],
\end{aligned}
$$

with $D=\phi_{v}\left(T_{1}-t\right) \phi_{m}\left(T_{2}-t\right)-\phi_{v}\left(T_{2}-t\right) \phi_{m}\left(T_{1}-t\right)$. The intertemporal hedging demand coefficients $h_{v}(u)$ and $h_{m}(u)$ solve the following ordinary differential equations:

$$
\begin{aligned}
h_{v}^{\prime}(u)= & \frac{1}{2 \eta} \sigma_{v}^{2} h_{v}(u)^{2}+\left(\frac{1-\eta}{\eta} \sigma_{v} \gamma^{v}-\kappa_{v}^{\mathbb{P}}\right) h_{v}(u) \\
& +\frac{1-\eta}{2 \eta}\left(\gamma^{v}\right)^{2}
\end{aligned}
$$




$$
\begin{aligned}
h_{m}^{\prime}(u)= & \frac{1}{2 \eta} \sigma_{m}^{2} h_{m}(u)^{2}+\kappa_{v} h_{v}(u)+\left(\frac{1-\eta}{\eta} \sigma_{m} \gamma^{m}-\kappa_{m}^{\mathbb{P}}\right) h_{m}(u) \\
& +\frac{1-\eta}{2 \eta}\left(\gamma^{m}\right)^{2}
\end{aligned}
$$

starting at $h_{v}(0)=h_{m}(0)=0$.

As shown in Merton (1971), the optimal allocation to risky assets includes 2 components: a myopic component that is proportional to the mean excess return, and an intertemporal hedging demand that is proportional to the covariance between the risky asset returns and the state variables that govern the stochastic investment opportunity, both scaled by the covariance matrix of the asset return. In our application, the stochastic variance risk represents the stochastic investment opportunity, which induces an intertemporal hedging demand when we invest in either the stock index alone as in equation (41) or the variance swap contracts alone as in equations (43) and (44).

Interestingly, when we invest in both the stock index and the 2 variance swap contracts to span both the return risk and the variance risks, the optimal investment in the stock index in equation (38) no longer includes an intertemporal hedging demand. Stochastic investment opportunities ask for intertemporal hedging demand; yet an appropriately designed derivative contract can be used to span the risk inherent in the stochastic investment opportunities and to eliminate the need for intertemporal hedging with the primary security.

Inspecting the optimal investment decisions in the variance swap contracts in equations (39) and (40), we observe that at short investment horizons, the optimal allocations in the 2 variance swap contracts depend on the market prices of the independent variance rate risk $\left(\gamma^{z}\right)$ and the central tendency risk $\left(\gamma^{m}\right)$, as well as the exposures of the 2 contracts to the 2 sources of risk, $\phi_{v}\left(T_{i}-t\right)$ and $\phi_{m}\left(T_{i}-t\right)$, with $i=1,2$. If we assume $T_{1}<T_{2}$ such that the 1 st contract is a short-term variance swap contract and the 2nd is a long-term contract, we have $\phi_{v}\left(T_{1}-t\right)>$ $\phi_{v}\left(T_{2}-t\right)$ and $\phi_{m}\left(T_{1}-t\right)<\phi_{m}\left(T_{2}-t\right)$. The common denominator $D$ is a positive quantity. Thus, investment in the long-term contract depends more on the market price of the central tendency factor, and investment in the short-term contract depends more on the market price of the independent variance rate risk.

When the 2nd variance swap contract has a sufficiently long maturity, its loading on the central tendency factor dominates its loading on the instantaneous variance rate, $\phi_{m}\left(T_{2}-t\right) \gg \phi_{v}\left(T_{2}-t\right)$. In this case, investment in the 1 st variance swap contract is mainly determined by the market price of the independent variance rate risk $\gamma^{z}$. Analogously, when the 1 st variance swap contract has a sufficiently short maturity, its loading on the instantaneous variance rate dominates its loading on the central tendency factor, $\phi_{v}\left(T_{1}-t\right) \gg \phi_{m}\left(T_{1}-t\right)$. In this case, investment in the 2 nd variance swap contract is mainly determined by the market price of the central tendency risk $\gamma^{m}$. Negative market prices on the 2 sources of risks lead to short positions in both variance swap contracts.

When the maturity separation between the 2 contracts is moderate, optimal allocations to the 2 variance swap contracts also depend on the relative magnitude of the 2 market prices $\gamma^{z}$ and $\gamma^{m}$. For example, our estimate for $\gamma^{z}$ is much larger than our estimate for $\gamma^{m}$ in absolute magnitude. In this case, the $\gamma^{z}$ term can 
dominate the investment decision, and the optimal allocations can include short positions in the short-term variance swap contract, but long positions in the longterm variance swap contract.

The intertemporal hedging demands for the 2 variance swap contracts are determined by the 2 coefficients $h_{v}(u)$ and $h_{m}(u)$ for the 2 variance risk exposures, which start at 0 for a myopic investor $(u=0)$. Since the constant terms in the 2 ordinary differential equations (35) and (36) are negative, the hedging demand coefficients become negative as the investment horizon increases.

\section{Empirical Analysis of Variance Swap Investments}

In this section, we combine the theoretical results on optimal allocations in Section V with the parameter estimates on the variance risk dynamics in Section IV to analyze the optimal allocations to the stock index and the variance swap contracts. We also perform historical analysis on the investment performance of different investment strategies.

\section{A. Optimal Allocation Weights}

Section IV estimated the variance risk dynamics during different subsample periods. To compute the optimal allocation weights, we also need to estimate the index return dynamics. Through an Euler approximation of the dynamics, we have

$$
\begin{aligned}
\mathrm{ER}_{t+1} & =\left(\gamma^{S}-\frac{1}{2}\right) v_{t} \Delta t+\sqrt{v_{t} \Delta t} \varepsilon_{t+1}^{S}, \\
v_{t+1} & =\left(\kappa_{v} m_{t}-\kappa_{v}^{\mathbb{P}} v_{t}\right) \Delta t+\sigma_{v} \sqrt{v_{t} \Delta t} \varepsilon_{t+1}^{v}, \\
m_{t+1} & =\kappa_{m}^{\mathbb{P}}\left(\theta_{m}^{\mathbb{P}}-m_{t}\right) \Delta t+\sigma_{m} \sqrt{m_{t} \Delta t} \varepsilon_{t+1}^{m},
\end{aligned}
$$

where $\mathrm{ER}_{t+1}$ denotes the weekly log excess return on the $\mathrm{S} \& \mathrm{P} 500$ index, $\Delta t=$ $7 / 365$ denotes the weekly sampling interval, and $\left(\varepsilon_{t+1}^{S}, \varepsilon_{t+1}^{v}, \varepsilon_{t+1}^{m}\right)$ denotes 3 standard normal variables with $\operatorname{cov}\left(\varepsilon_{t+1}^{S}, \varepsilon_{t+1}^{v}\right)=\rho$ and with $\varepsilon_{t+1}^{m}$ independent of the other 2 normal variables. We obtain the total returns on the index from Bloomberg and compute the excess return against the corresponding 1-week U.S. dollar London Interbank Offered Rate (LIBOR) interest rate. Holding fixed the previous estimates on the parameters that govern the variance dynamics, we can estimate $\gamma^{S}$ and $\rho$ with a simple maximum likelihood method by regarding the extracted time series on $\left(v_{t}, m_{t}\right)$ as observables. The conditional likelihood for each set of observation is given by

$$
l_{t}\left(y_{t+1}, \Theta\right)=-\frac{1}{2}\left[\ln \left|\Sigma_{t}\right|+\left(y_{t+1}-\mu_{t}\right)^{\top}\left(\Sigma_{t}\right)^{-1}\left(y_{t+1}-\mu_{t}\right)\right]
$$

with

$$
y_{t+1}=\left[\begin{array}{c}
\mathrm{ER}_{t+1} \\
v_{t+1} \\
m_{t+1}
\end{array}\right], \quad \Sigma_{t}=\left[\begin{array}{ccc}
v_{t} & v_{t} \sigma_{v} \rho & 0 \\
v_{t} \sigma_{v} \rho & \sigma_{v}^{2} v_{t} & 0 \\
0 & 0 & \sigma_{m}^{2} m_{t}
\end{array}\right] \Delta t
$$




$$
\mu_{t}=\left[\begin{array}{c}
\left(\gamma^{S}-\frac{1}{2}\right) v_{t} \\
\left(\kappa_{v} m_{t}-\kappa_{v}^{\mathbb{P}} v_{t}\right) \\
\kappa_{m}^{\mathbb{P}}\left(\theta_{m}^{\mathbb{P}}-m_{t}\right)
\end{array}\right] \Delta t
$$

Table 6 reports the estimates on $\gamma^{S}$ and $\rho$ during different sample periods. For the full sample period, the market price of return risk $\left(\gamma^{S}\right)$ is estimated at 1.6886 and the correlation $(\rho)$ is estimated at -0.7463 . From the estimates, we also compute the market price of the independent variance risk $\gamma^{z}=\left(\gamma^{v}-\rho \gamma^{S}\right) / \sqrt{1-\rho^{2}}$ and report the value in the last row. For the full sample period, the market price of the independent variance risk is strongly negative at -22.7105 . When we reestimate the dynamics for 2 subsamples, we obtain a higher market price of return risk estimate but a slightly lower correlation estimate for the 1st subsample than for the 2nd subsample. Accordingly, the market price of the independent variance risk becomes larger during the 2 nd subsample period.

TABLE 6

Market Price of Return Risk and Correlation

Entries report the maximum likelihood parameter estimates and the absolute magnitudes of $t$-values (in parentheses) of the market price of return risk $\left(\gamma^{S}\right)$ and the instantaneous correlation $(\rho)$ between the return risk and the instantaneous variance rate risk. The estimation is performed on weekly returns, with the extracted variance risk factors $\left(v_{t}, m_{t}\right)$ treated as observables. We perform the estimation at both 2 subsamples and the full sample. The 1 st subsample is from January 10, 1996 to June 27, 2001, 286 weekly observation for each series. The 2nd subsample is from July 4, 2001 to March 28, 2007, 300 weekly observations for each series. The last row reports the market price of independent risk

$$
\gamma^{z}=\left(\gamma^{v}-\rho \gamma^{S}\right) / \sqrt{1-\rho^{2}}
$$

where the corresponding estimates for $\gamma^{\vee}$ are from Tables 3 and 4 .

\begin{tabular}{lccc} 
Parameters & \multicolumn{1}{c}{$1996-2001$} & $2001-2007$ & $1996-2007$ \\
\cline { 2 - 3 }$\gamma^{S}$ & 2.1386 & 0.8125 & 1.6886 \\
& $(0.99)$ & $(1.33)$ & $(1.68)$ \\
$\rho$ & -0.7339 & -0.7924 & -0.7463 \\
$\gamma^{z}$ & $(11.29)$ & $(0.27)$ & $(14.11)$ \\
\hline
\end{tabular}

The market price of variance risk has been found to be highly negative in several studies (e.g., Bakshi and Kapadia (2003a), Bondarenko (2004), and Carr and $\mathrm{Wu}$ (2009)). A new stream of literature tries to rationalize the magnitude of the risk premium based on biased beliefs and peso problems (Bondarenko (2003)), path-dependent preferences (Bates (2008)), ambiguity aversion (Liu, Pan, and Wang (2005)), net-buying and demand pressure (Bollen and Whaley (2004), Gârleanu, Pedersen, and Poteshman (2009)), short-selling constraints (Isaenko (2007)), and margin requirements (Santa-Clara and Saretto (2009)). In this paper, we do not attempt to rationalize the magnitude of the variance risk premium. Instead, we study how an investor alters her asset allocation decision to benefit from the risk premium by including variance swap contracts in her investment portfolios.

Given the parameter estimates, we compute the allocation weights to the stock index and the variance swap contracts. The key determinants of the allocation weights are the market prices of the 3 sources of risk: the return risk $\left(\gamma^{S}\right)$, the independent variance risk $\left(\gamma^{z}\right)$, and the central tendency risk $\left(\gamma^{m}\right)$. Intuitively, the 
market price of the return risk determines the position in the stock index, the market price of the independent variance risk determines the position in the short-term variance swap contract, and the market price of the central tendency determines the allocation to the long-term variance swap contract. Through cross correlations in the risky assets, the market price of variance risk also enters the allocation in the stock index, and the market prices on the 2 sources of variance risks both enter the investments in the 2 variance swap contracts, the relative degree of which is determined by the maturity differences.

To study how the allocation weights vary with the market price estimates, we fix an investment horizon of 2 months, and we take the full-sample parameter estimates in Tables 3 and 6 as our benchmarks. We vary the market prices of the 3 sources of risks $\left(\gamma^{S}, \gamma^{z}\right.$, and $\left.\gamma^{m}\right)$ around their respective estimates and investigate how the allocation weights change with the varying market prices. In our calculation, we choose a high relative risk aversion $(\eta=200)$ to counter the high negative market price of variance risk so that the investments are not overly levered.

Figure 3 plots the optimal portfolio weights on the stock index $(w)$ as a function of the market prices of return risk $\left(\gamma^{S}\right)$ and independent variance risk $\left(\gamma^{z}\right)$. Graph A plots the optimal allocation in the absence of variance swap contracts in the decision. In this case, the fraction of wealth invested in the stock index is mainly determined by the market price of return risk. The positive market price of return risk $\left(\gamma^{S}\right)$ generates long positions in the stock index. The fraction of wealth invested in the stock index increases as the market price of return risk $\gamma^{S}$ increases. The market price of variance risk affects the intertemporal hedging demand through its impact on $\kappa_{v}^{\mathbb{P}}=\kappa_{v}-\left(\rho \gamma^{S}+\sqrt{1-\rho^{2}} \gamma^{z}\right) \sigma_{v}$. The negative market price of variance risk makes the hedging demand more negative and hence reduces the investment in the stock index. Nevertheless, as Chacko and Viceira (2005) have observed, the intertemporal hedging demand on the stock index induced by stochastic volatility is small. Therefore, when the stock index is the only risky asset in the investment decision, its allocation is mainly determined by the market price of return risk.

\section{FIGURE 3}

\section{Optimal Investment in the Stock Index With and Without Variance Swap Contracts}

Graphs A and B of Figure 3 plot the optimal fractions of wealth invested in the stock index $(w)$ as the market prices of return risk $\left(\gamma^{S}\right)$ and the market price of variance risk $\left(\gamma^{Z}\right)$ vary. Graph A plots the optimal investment without the presence of variance swap contracts. Graph B plots the investment with the presence of 2 variance swap contracts at 2-month and 2-year maturities.

Graph A. Without Variance Swaps

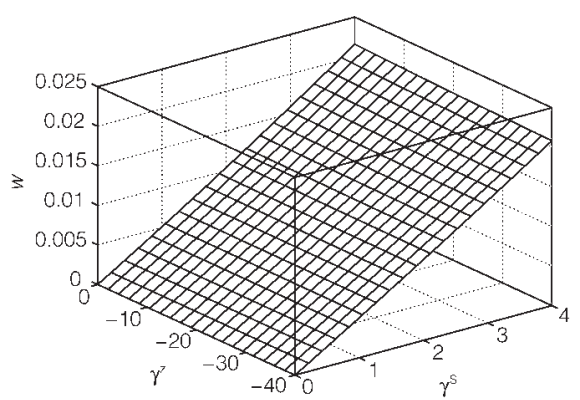

Graph B. With Variance Swaps

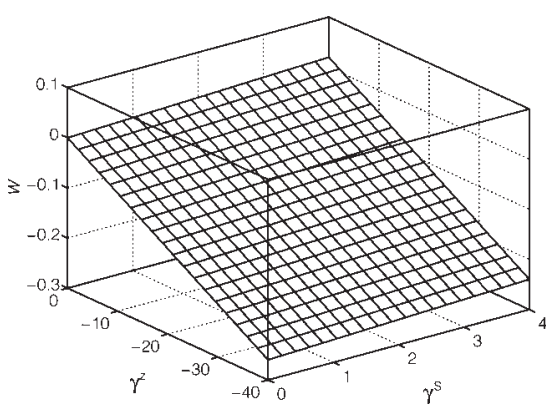


The dependence structure changes dramatically when the variance swap contracts become available to the investor. Graph B of Figure 3 plots the optimal fraction of wealth invested in the stock index when 2 variance swap contracts (at 2-month and 2-year maturities) are also part of the investment portfolio. In this case, both the market price of return risk $\left(\gamma^{S}\right)$ and the market price of variance risk $\left(\gamma^{z}\right)$ enter the investment decision in the stock index. With 0 market price on the variance risk, it remains optimal to take long positions in the stock index and to increase the long position with increasing market price of the return risk. However, our estimate of the market price of variance risk is strongly negative. The strongly negative market price of variance risk makes it optimal to take short positions in the stock index. The short position in the stock index increases as the market price of variance risk $\gamma^{z}$ becomes more negative.

Figure 4 shows the dependence of the optimal variance swap investments on the market prices of the 2 sources of variance risks. Signing variance swap contracts has 0 initiation costs. We measure the investment by the notional value as fractions of the total wealth $(n)$. Under the 2-factor variance risk model, any 2 variance swap contracts of different maturities can span the 2 sources of variance risks. We choose the 2 variance swap contracts at 2-month and 2-year maturities in Graph A, and at 6-month and 1-year maturities in Graph B. Since the market price estimate of the instantaneous variance risk $\left(\gamma^{z}\right)$ is much more negative at around -20 than the market price estimate of the central tendency factor $\left(\gamma^{m}\right)$ at less than -1 , it is generally optimal to take short positions in the short-term variance swap contract and long positions in the long-term variance swap contract. Hence, in Figure 4, the surface on top in each graph represents the optimal allocation weights to the long-term variance swap contract, and the surface below represents the optimal allocation weights to the short-term variance swap contract. The distance between the 2 surfaces increases as the difference between the market prices of the 2 sources of risks increases. When the market price of the

\section{FIGURE 4}

\section{Optimal Investment in Variance Swap Contracts}

Graphs A and B of Figure 4 plot the optimal investment in variance swap contracts (notional in fractions of total wealth, $n$ ) as a function of the market price of the instantaneous variance risk $\left(\gamma^{z}\right)$ and the market price of the central tendency risk $\left(\gamma^{m}\right)$. Graph A plots the investment in 2-month and 2-year variance swap contracts. Graph B plots the investment in 6-month and 1-year variance swap contracts.

Graph A. $T_{1}=2$ Months, $T_{2}=2$ Years

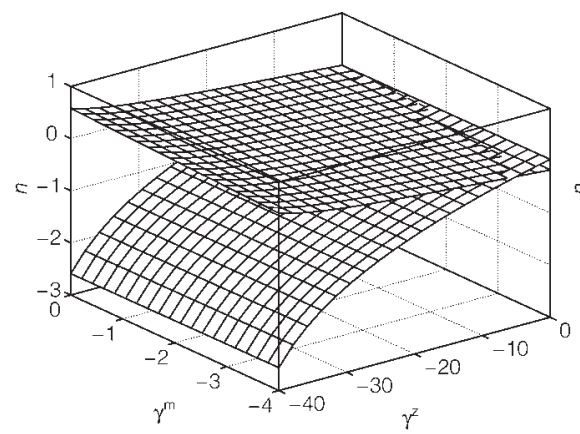

Graph B. $T_{1}=6$ Months, $T_{2}=1$ Year

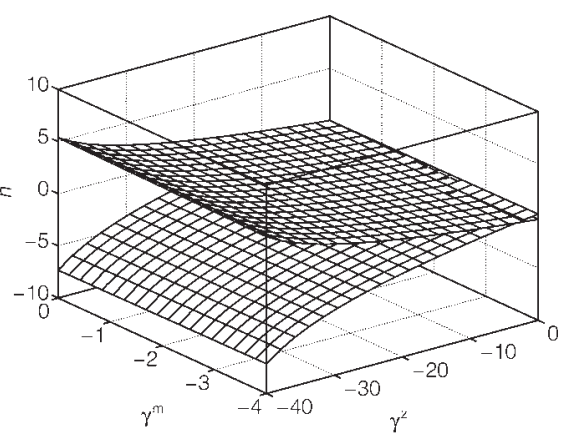


instantaneous variance risk becomes less negative than the market price of the central tendency factor, the 2 surfaces start to cross with each other, and it becomes optimal to take short positions in the long-term contract and long positions in the short-term contract. With the market prices fixed, comparing the 2 graphs shows that the maturity differences between the 2 variance swap contracts also affect the distance between the 2 surfaces. The distance is larger when the maturity difference between the 2 contracts is smaller. Therefore, in practice, it is often appropriate to choose the 2 maturities to be wide apart to reduce the absolute positions (and hence leverage) in the investments.

Compared with the traditional stock-only portfolio, the optimal allocation decision in the presence of variance swap contracts reacts strongly to the highly negative variance risk premium. The investor reaps the large variance risk premium by taking short positions in the short-term variance swap contract. To hedge part of the variance risk, the investor goes long on the long-term variance swap contract and short on the stock index. The long position in the long-term variance swap contract helps to dampen the effect of persistent increases in the volatility level. Furthermore, given the large negative correlation between index returns and return variance, a short position in the stock index serves as an additional hedge against adverse movements in the short-term variance factor. This hedge is particularly effective against volatility spikes during sharp market downturns.

\section{B. Historical Investment Performance}

To gauge the historical performance of different investment strategies, we perform the following investment exercise: First, we compute the optimal portfolio weights for 3 investment strategies using parameter estimates from the first half of the sample from January 10, 1996 to June 27, 2001. The 3 strategies are

$\mathcal{S}_{1}$ : Invest in the stock index and 2 variance swap contracts.

$\mathcal{S}_{2}$ : Invest in 2 variance swap contracts only.

$\mathcal{S}_{3}$ : Invest in the stock index only.

In all 3 strategies, we have access to the money market account to balance out the investments. We assume that cash saved in the money market account makes a risk-free return given by the corresponding U.S. dollar LIBOR interest rate. For the first 2 strategies, $\mathcal{S}_{1}$ and $\mathcal{S}_{2}$, we choose the 2 variance swap contracts that have the largest maturity differences at 2-month and 2-year maturities. As we have shown in the previous subsection, choosing swap contracts with wider maturity spreads lead to smaller absolute positions in both contracts.

Given the fixed model parameters, the optimal allocation weights as fractions of the total wealth are fixed. For all 3 strategies, we choose an investment horizon of 2 months. For the first 2 strategies that involve variance swap investments, we use a high relative risk aversion of $\eta=200$ to counteract the highly negative variance risk premium. Under these conditions, the portfolio for the 1st strategy $\mathcal{S}_{1}$ includes a short position in the stock of $w=-0.1061$, a short position in the 2month variance swap of $n_{1}=-0.6717$, and a long position in the 2-year variance swap of $n_{2}=0.1397$. The portfolio for strategy $\mathcal{S}_{2}$ includes a short position in the 
2-month variance swap contract of $n_{1}=-0.3513$ and a long position in the 2-year variance swap contract of $n_{2}=0.0644$. For the stock-index-only strategy $\mathcal{S}_{3}$, since the market price of the return risk is relatively low, we use a lower relative risk aversion of $\eta=3$ to generate an allocation in the stock index at $w=0.7265$. The relative risk aversion coefficient controls the size and hence financial leverage of the risky investment, but it has little effect on normalized performance measures such as the Sharpe (1966) ratio.

Chacko and Viceira (2005) argue that the presence of stochastic volatility has only a small effect on the asset allocation decision. They are correct when the investor can only invest in the stock index. In our 3rd strategy $\mathcal{S}_{3}$ with the stock index as the only available risky asset, the fraction of wealth invested in the index is 0.7265 , of which 0.7129 is from the myopic demand and only 0.0136 is from the intertemporal hedging demand induced by the presence of stochastic volatility. However, the picture changes drastically when the investor has access to variance swap contracts. In this case, the investor can use the variance swap contracts to gain access to the large variance risk premium. Without stochastic volatility and variance risk premium, there is no need to invest in the variance swap contract, and the allocation to the stock index is positive given the positive return risk premium. With stochastic volatility and highly negative variance risk premium, it becomes optimal to take short positions in a short-term variance swap contract and also short positions in the stock index. With access to variance swap contracts, the presence of stochastic volatility and variance risk premium alter the investment decision drastically.

For each strategy, we perform an investment exercise starting on January 10, 1996 with an investment horizon of 2 months. After 2 months, we liquidate the portfolio at the available market prices, calculate the corresponding portfolio returns, and then start a new investment. This exercise generates a nonoverlapping time series of 2-month returns for each strategy. To make full use of the data series, we repeat this investment exercise starting on the 8 different Wednesdays during the first 2 months of the sample. We compare the statistics of the 8 nonoverlapping return series generated from different starting dates.

The return calculation on the stock index and the money market account is straightforward. The first 2 strategies $\mathcal{S}_{1}$ and $\mathcal{S}_{2}$ also include investments in 2 variance swap contracts. The 1 st variance swap contract has a 2 -month maturity and hence expires at the end of each 2-month investment horizon. The profit and loss can be calculated based on the difference between the annualized realized variance over the 2-month horizon and the variance swap rate at the start of the exercise. Multiplying the variance difference by the dollar notional amount invested in the contract generates the dollar profit and loss,

$$
\mathrm{PL}_{1}=N_{1}\left(\mathrm{RV}_{t, T_{1}}-\mathrm{VS}_{t}\left(T_{1}\right)\right)
$$

where $\mathrm{RV}_{t, T_{1}}$ denotes the annualized realized variance during the 2-month period $\left[t, T_{1}\right]$, with $t$ being the investment time and $T_{1}$ being the end of the investment horizon. Given the fixed allocation fraction $\left(n_{1}\right)$ in terms of the total wealth, the dollar notional invested at time $t$ is $N_{1}=n_{1} W_{t}$, where $W_{t}$ denotes the wealth level at time $t$. 
The 2 nd variance swap contract has a 2 -year maturity. The profit and loss at the end of the 2-month investment horizon can be computed as

$$
\mathrm{PL}_{2}=N_{2}\left(\omega \mathrm{RV}_{t, T_{1}}+(1-\omega) \mathrm{VS}_{T_{1}}\left(T_{2}\right)-\mathrm{VS}_{t}\left(T_{2}\right)\right)
$$

where $\omega=\left(T_{1}-t\right) /\left(T_{2}-t\right)$ denotes the fraction of time passed over the original maturity of the swap contract and $\mathrm{VS}_{T_{1}}\left(T_{2}\right)$ is the time- $T_{1}$ variance swap rate that expires at $T_{2}$. In this case, the profit and loss come from 2 sources: One is the realization of return variance over the past 2 months, the other is the new variance swap rate at the same expiry date $\mathrm{VS}_{T_{1}}\left(T_{2}\right)$. Since the variance swap rates are quoted at fixed times to maturity, we perform piece-wise linear total variance interpolation on the time- $T_{1}$ variance swap rate term structure to obtain the value for $\mathrm{VS}_{T_{1}}\left(T_{2}\right)$.

For each strategy, we repeat the exercise 8 times with different starting dates to generate 8 nonoverlapping time series of 2-month returns. We compute the summary statistics on the excess returns for each series and report the average statistics over the 8 time series for each strategy in Table 7. Both the mean excess return and the standard deviations are reported in annualized percentages. For the 1 st strategy $\mathcal{S}_{1}$, which includes both the stock index and variance swaps, the mean excess return over the whole sample period averages $5.153 \%$, the standard deviation averages $3.705 \%$, and the Newey-West (1987) serial dependence-adjusted standard deviation averages larger at 3.886\%. The annualized Sharpe (1966) ratio, which is computed as the mean excess return over the Newey-West standard deviation, averages 1.461. The excess return shows large excess kurtosis and positive skewness.

\section{TABLE 7}

Summary Statistics of Investment Strategies

\begin{tabular}{|c|c|c|c|c|c|c|}
\hline \multicolumn{7}{|c|}{$\begin{array}{l}\text { Entries report the sample averages of the mean, standard deviation (Std), skewness (Skew), excess kurtosis (Kurt), and } \\
\text { Newey-West (1987) serial dependence-adjusted standard deviation (Newey) of the excess returns from } 3 \text { different invest- } \\
\text { ment strategies. The mean and standard deviations are in annualized percentages. The last column reports the annualized } \\
\text { Sharpe (1966) ratio defined as the mean excess return divided by the Newey-West standard deviation. The } 1 \text { st strategy } \\
\mathcal{S}_{1} \text { invests in both the stock index and } 2 \text { variance swap contracts at } 2 \text {-month and } 2 \text {-year maturities, respectively. The } 2 \text { nd } \\
\text { strategy } \mathcal{S}_{2} \text { invests in the } 2 \text { variance swaps only. The } 3 r d \text { strategy } \mathcal{S}_{3} \text { invests in the stock index only. All strategies have an } \\
\text { investment horizon of } 2 \text { months. We start each strategy at } 8 \text { different Wednesdays during the first } 2 \text { months of our sample to } \\
\text { generate } 8 \text { time series of nonoverlapping } 2 \text {-month excess returns. The statistics in Table } 7 \text { represent the average statistics } \\
\text { of the } 8 \text { series for each strategy. We report the full-sample statistics in Panel A, the in-sample statistics from January } 1996 \\
\text { to June } 2001 \text { in Panel B, and the out-of-sample statistics for the remaining sample period in Panel C. }\end{array}$} \\
\hline Strategy & Mean & Std & Skew & Kurt & Newey & Sharpe \\
\hline \multicolumn{7}{|c|}{ Panel A. Whole Sample Period (January 1996-March 2007) } \\
\hline $\begin{array}{l}\mathcal{S}_{1} \\
\mathcal{S}_{2} \\
\mathcal{S}_{3}\end{array}$ & $\begin{array}{l}5.153 \\
2.922 \\
2.842\end{array}$ & $\begin{array}{r}3.705 \\
2.263 \\
10.130\end{array}$ & $\begin{array}{r}1.210 \\
1.083 \\
-0.175\end{array}$ & $\begin{array}{l}7.552 \\
7.978 \\
0.678\end{array}$ & $\begin{array}{l}3.886 \\
2.338 \\
9.601\end{array}$ & $\begin{array}{l}1.461 \\
1.376 \\
0.325\end{array}$ \\
\hline \multicolumn{7}{|c|}{ Panel B. In-Sample Period (January 1996-June 2001) } \\
\hline $\begin{array}{l}\mathcal{S}_{1} \\
\mathcal{S}_{2} \\
\mathcal{S}_{3}\end{array}$ & $\begin{array}{l}6.369 \\
3.694 \\
4.575\end{array}$ & $\begin{array}{r}4.331 \\
2.611 \\
10.958\end{array}$ & $\begin{array}{r}1.365 \\
1.405 \\
-0.035\end{array}$ & $\begin{array}{l}5.796 \\
6.418 \\
0.383\end{array}$ & $\begin{array}{l}4.141 \\
2.492 \\
9.881\end{array}$ & $\begin{array}{l}1.716 \\
1.664 \\
0.509\end{array}$ \\
\hline \multicolumn{7}{|c|}{ Panel C. Out-of-Sample Period (July 2001-March 2007) } \\
\hline $\begin{array}{l}\mathcal{S}_{1} \\
\mathcal{S}_{2} \\
\mathcal{S}_{3}\end{array}$ & $\begin{array}{l}3.996 \\
2.188 \\
1.193\end{array}$ & $\begin{array}{l}2.878 \\
1.806 \\
9.361\end{array}$ & $\begin{array}{r}0.015 \\
-0.214 \\
-0.516\end{array}$ & $\begin{array}{l}4.512 \\
5.721 \\
1.005\end{array}$ & $\begin{array}{l}3.429 \\
2.015 \\
9.262\end{array}$ & $\begin{array}{l}1.287 \\
1.203 \\
0.142\end{array}$ \\
\hline
\end{tabular}


For the variance swap-only strategy $\mathcal{S}_{2}$, the mean excess return over the whole sample period averages $2.922 \%$, the standard deviation averages $2.263 \%$, and the annualized Sharpe (1966) ratio averages 1.376, lower than the average Sharpe ratio from $\mathcal{S}_{1}$. For the stock index-only strategy $\mathcal{S}_{3}$, the mean excess return averages lower at $2.842 \%$, but the standard deviation averages much higher at $10.13 \%$. As a result, the Sharpe ratio of 0.325 is much lower than that from the other 2 strategies.

The Sharpe (1966) ratio difference between the stock-only strategy $\mathcal{S}_{3}$ and the other 2 strategies shows the benefit of exploiting the large variance risk premiums. The Sharpe ratio difference between $\mathcal{S}_{1}$ and $\mathcal{S}_{2}$ further shows that it is beneficial to use the stock index to hedge against the variance risk.

Since the portfolio weights are computed based on the parameter estimates from the first half of the data sample, returns during the 1st half of the sample represent in-sample returns, and returns during the 2 nd half are out of sample. In Panels B and C of Table 7, we separately compute the summary statistics for the in-sample and the out-of-sample excess returns. For all 3 strategies, both the mean excess returns and the standard deviations are lower during the more recent outof-sample period. The Sharpe (1966) ratio estimates are also lower. Nevertheless, the performance rankings among the 3 strategies remain the same during the insample and the out-of-sample periods.

\section{Concluding Remarks}

Using more than a decade worth of variance swap quotes on the S\&P 500 index across 5 fixed times to maturity, we design and estimate affine models of variance risk dynamics to capture the historical behavior of the term structure of variance swap rates. We find that 2 stochastic variance risk factors are needed to explain the term structure variation of the variance swap rates, with 1 factor controlling the instantaneous variance rate while the other controls the central tendency of the variance rate movements. The variance rate factor is much more transient than the central tendency factor under both the risk-neutral and the statistical measures, thus generating different loading patterns across the term structure from the 2 risk factors and different autocorrelation patterns for variance swap rates of different maturities. We also find that the market prices of both variance risk factors are negative, but the absolute magnitude of the market price is much higher for the instantaneous variance rate risk than for the central tendency factor.

Embedding variance swaps into an optimal investment strategy, an investor drastically changes her asset allocation decision. The intertemporal hedging demand is completely removed from the stock investment. Moreover, given the large and negative estimate for the market price of variance risk, it becomes optimal for the investor to take a short position in both a short-term variance swap contract and the stock index, while taking a long position in a long-term variance swap contract. A historical investment exercise shows that incorporating both the stock index and the variance swap contracts in the investment portfolio markedly improves the investment performance, both in sample and out of sample.

Compared to traditional mean variance analysis on primary securities, the modern financial industry has recognized the important impacts that stock price 
jumps and stochastic variance can have on an investor's welfare. Accordingly, derivative securities such as options and variance swaps have been developed to span risks along these 2 dimensions. To simplify the problem and to gain a clear picture of their separate effects, the academic literature either assumes constant volatility and focuses on how to choose options at different strikes to span the random jump risk in the stock price (Carr and Madan (2001), Carr and Wu (2002)), or assumes purely continuous dynamics (or jumps of fixed size) and focuses on how to choose options to span the stochastic variance risk (Liu and Pan (2003)). We contribute to the latter literature by showing that using variance swap contracts across different maturities represents a more direct way of identifying variance risk dynamics and spanning the variance risks. Integrating these 2 dimensions can be a challenging but interesting direction for future research.

\section{References}

Aït-Sahalia, Y., and R. Kimmel. "Maximum Likelihood Estimation of Stochastic Volatility Models." Journal of Financial Economics, 83 (2007), 413-452.

Aït-Sahalia, Y., and L. Mancini. "Out of Sample Forecasts of Quadratic Variation." Journal of Econometrics, 147 (2008), 17-33.

Aït-Sahalia, Y.; P. Mykland; and L. Zhang. "How Often to Sample a Continuous-Time Process in the Presence of Market Microstructure Noise." Review of Financial Studies, 18 (2005), 351-416.

Andersen, T. G.; T. Bollerslev; F. X. Diebold; and H. Ebens. "The Distribution of Realized Stock Return Volatility.” Journal of Financial Economics, 61 (2001), 43-76.

Andersen, T. G.; T. Bollerslev; F. X. Diebold; and P. Labys. "Modeling and Forecasting Realized Volatility." Econometrica, 71 (2003), 579-625.

Andersen, T.; T. Bollerslev; and N. Meddahi. "Correcting the Errors: Volatility Forecast Evaluation Using High-Frequency Data and Realized Volatilities.” Econometrica, 73 (2005), 279-296.

Andreou, E., and E. Ghysels. "Rolling-Sample Volatility Estimators: Some New Theoretical, Simulation, and Empirical Results." Journal of Business and Economic Statistics, 20 (2002), 363-376.

Bakshi, G., and N. Kapadia. "Delta-Hedged Gains and the Negative Market Volatility Risk Premium." Review of Financial Studies, 16 (2003a), 527-566.

Bakshi, G., and N. Kapadia. "Volatility Risk Premiums Embedded in Individual Equity Options: Some New Insights.” Journal of Derivatives, 11 (2003b), 45-54.

Balduzzi, P.; S. Das; and S. Foresi. "The Central Tendency: A Second Factor in Bond Yields.” Review of Economics and Statistics, 80 (1998), 62-72.

Bandi, F. M., and J. R. Russell. "Separating Microstructure Noise from Volatility." Journal of Financial Economics, 79 (2006), 655-692.

Barndorff-Nielsen, O. E., and N. Shephard. "Econometric Analysis of Realized Covariation: High Frequency Based Covariance, Regression, and Correlation in Financial Economics." Econometrica, 72 (2004a), 885-925.

Barndorff-Nielsen, O. E., and N. Shephard. "Power and Bipower Variation with Stochastic Volatility and Jumps." Journal of Financial Econometrics, 2 (2004b), 1-37.

Bates, D. "Jumps and Stochastic Volatility: Exchange Rate Processes Implicit in Deutsche Mark Options." Review of Financial Studies, 9 (1996), 69-107.

Bates, D. "Post-' 87 Crash Fears in the S\&P 500 Futures Option Market." Journal of Econometrics, 94 (2000), 181-238.

Bates, D. "Empirical Option Pricing: A Retrospection.” Journal of Econometrics, 116 (2003), 387404.

Bates, D. “The Market for Crash Risk.” Journal of Economic Dynamics and Control, 32 (2008), 22912321.

Bergomi, L. "Smile Dynamics.” Risk, 17 (2004), 117-123.

Bergomi, L. "Smile Dynamics II." Risk, 18 (2005), 67-73.

Bergomi, L. "Smile Dynamics III.” Risk, 21 (2008), 90-96.

Black, F., and M. Scholes. "The Pricing of Options and Corporate Liabilities." Journal of Political Economy, 81 (1973), 637-654.

Bollen, N. P., and R. E. Whaley. "Does Net Buying Pressure Affect the Shape of Implied Volatility Functions?" Journal of Finance, 59 (2004), 711-753. 
Bondarenko, O. "Why Are Put Options So Expensive?" Working Paper, University of Illinois at Chicago (2003).

Bondarenko, O. "Market Price of Variance Risk and Performance of Hedge Funds." Working Paper, University of Illinois at Chicago (2004).

Broadie, M.; M. Chernov; and M. Johannes. "Model Specification and Risk Premia: Evidence from Futures Options." Journal of Finance, 62 (2007), 1453-1490.

Buehler, H. "Consistent Variance Curve Models.” Finance and Stochastics, 10 (2006), 178-203.

Carr, P.; X. Jin; and D. Madan. "Optimal Investment in Derivative Securities." Finance and Stochastics, 5 (2001), 33-59.

Carr, P.; R. Lee; and L. Wu. "Variance Swaps on Time-Changed Lévy Processes." Finance and Stochastics, forthcoming (2010).

Carr, P., and D. Madan. "Optimal Positioning in Derivative Securities." Quantitative Finance, 1 (2001), 19-37.

Carr, P., and J. Sun. "A New Approach for Option Pricing under Stochastic Volatility." Review of Derivatives Research, 10 (2007), 87-150.

Carr, P., and L. Wu. "Static Hedging of Standard Options." Working Paper, New York University and Baruch College (2002).

Carr, P., and L. Wu. "A Tale of Two Indices.” Journal of Derivatives, 13 (2006), 13-29.

Carr, P., and L. Wu. "Leverage Effect, Volatility Feedback, and Self-Exciting Market Disruptions: Disentangling the Multi-Dimensional Variations in S\&P 500 Index Options." Working Paper, Bloomberg and Baruch College (2008).

Carr, P., and L. Wu. "Variance Risk Premiums." Review of Financial Studies, 22 (2009), 1311-1341.

Chacko, G., and L. M. Viceira. "Dynamic Consumption and Portfolio Choice with Stochastic Volatility in Incomplete Markets." Review of Financial Studies, 18 (2005), 1369-1402.

Chernov, M., and E. Ghysels. "A Study towards a Unified Approach to the Joint Estimation of Objective and Risk Neutral Measures for the Purpose of Options Valuation." Journal of Financial Economics, 56 (2000), 407-458.

Cox, D. R. "Some Statistical Methods Connected with Series of Events." Journal of the Royal Statistical Society, Series B, 17 (1955), 129-164.

Duanmu, Z. "Rational Pricing of Options on Realized Volatility: The Black Scholes Way." Working Paper, Merrill Lynch (2004).

Duffie, D. Dynamic Asset Pricing Theory. Princeton, NJ: Princeton University Press (1992).

Duffie, D.; J. Pan; and K. Singleton. "Transform Analysis and Asset Pricing for Affine Jump Diffusions." Econometrica, 68 (2000), 1343-1376.

Dupire, B. "Model Art.” Risk, 6 (1993), 118-124.

Engle, R. "Risk and Volatility: Econometric Models and Financial Practice." American Economic Review, 94 (2004), 405-420.

Eraker, B. "Do Stock Prices and Volatility Jump? Reconciling Evidence from Spot and Option Prices." Journal of Finance, 59 (2004), 1367-1403.

Gârleanu, N.; L. H. Pedersen; and A. M. Poteshman. "Demand-Based Option Pricing." Review of Financial Studies, 22 (2009), 4259-4299.

Hansen, P. R., and A. Lunde. "Realized Variance and Market Microstructure Noise." Journal of Business and Economic Statistics, 24 (2006), 127-161.

Heston, S. L. "Closed-Form Solution for Options with Stochastic Volatility, with Application to Bond and Currency Options." Review of Financial Studies, 6 (1993), 327-343.

Isaenko, S. "Dynamic Equilibrium with Overpriced Put Options." Economic Notes, 36 (2007), $1-26$.

Jackwerth, J. C. "Recovering Risk Aversion from Option Prices and Realized Returns." Review of Financial Studies, 13 (2000), 433-451.

Jones, C. S. "The Dynamics of Stochastic Volatility: Evidence from Underlying and Options Markets.” Journal of Econometrics, 116 (2003), 181-224.

Kalman, R. E. "A New Approach to Linear Filtering and Prediction Problems." Transactions of the ASME-Journal of Basic Engineering, 82 (1960), 35-45.

Liu, J., and J. Pan. "Dynamic Derivative Strategies." Journal of Financial Economics, 69 (2003), $401-430$.

Liu, J.; J. Pan; and T. Wang. "An Equilibrium Model of Rare-Event Premia and Its Implication for Option Smirks.” Review of Financial Studies, 18 (2005), 131-164.

Merton, R. C. "Optimum Consumption and Portfolio Rules in a Continuous-Time Model." Journal of Economic Theory, 3 (1971), 373-413.

Newey, W. K., and K. D. West. "A Simple, Positive Semi-Definite, Heteroskedasticity and Autocorrelation Consistent Covariance Matrix.” Econometrica, 55 (1987), 703-708. 
Oomen, R. C. A. "Properties of Bias-Corrected Realized Variance under Alternative Sampling Schemes." Journal of Financial Econometrics, 3 (2005), 555-577.

Pan, J. "The Jump-Risk Premia Implicit in Options: Evidence from an Integrated Time-Series Study." Journal of Financial Economics, 63 (2002), 3-50.

Santa-Clara, P., and A. Saretto. "Option Strategies: Good Deals and Margin Calls." Journal of Financial Markets, 12 (2009), 391-417.

Sharpe, W. F. “Mutual Fund Performance.” Journal of Business, 39 (1966), 119-138.

Wu, L. "Variance Dynamics: Joint Evidence from Options and High-Frequency Returns." Journal of Econometrics, forthcoming (2010).

Zhang, L.; P. A. Mykland; and Y. Aït-Sahalia. "A Tale of Two Time Scales: Determining Integrated Volatility with Noisy High-Frequency Data.” Journal of the American Statistical Association, 100 (2005), 1394-1411. 